\title{
Políticas públicas para una economía creativa en Jalisco y el área metropolitana de Guadalajara
}

\author{
Public Policies for a Creative Economy in Jalisco \\ and the Metropolitan Area of Guadalajara
}

\author{
Katia Magdalena Lozano Uvario* (D) https://orcid.org/0000-0003-3465-6086
}

\section{Resumen}

Objetivo: analizar el surgimiento y los tipos de políticas públicas que impulsan el desarrollo de las industrias culturales y creativas en Jalisco, México, con incidencia en el área metropolitana de Guadalajara. Metodología: es descriptiva y propone una tipología para el análisis de las políticas públicas con orientación a la economía creativa y sus impactos. Resultados: se hallaron 5 programas gubernamentales en los que las políticas sistémicas sobresalen en el fomento económico. Entre ellas, se encuentran el proyecto de Ciudad Creativa Digital y las políticas de oferta mediante financiamiento directo. La concentración y la especialización en las actividades creativas y culturales de Guadalajara y Zapopan han propiciado que se les reconozca como territorios creativos, con lo que se ha alentado la creación de políticas públicas de oferta y demanda, y de programas de formación de capital humano. Limitaciones: la información es insuficiente para valorar el impacto de las políticas públicas en los municipios. Valor: la investigación describe la forma en que las políticas públicas locales fomentan el desarrollo de la economía creativa en el espacio local. Conclusiones: el planteamiento de políticas públicas orientadas a la economía creativa tiene un trasfondo estructural y coyuntural, e impone retos para la disposición y la continuidad de recursos presupuestales, el desarrollo de capacidades empresariales e innovadoras y la consolidación de comunidades creativas.

Palabras clave: políticas públicas; economía creativa; desarrollo local; Guadalajara; Zapopan; Jalisco.

\section{Abstract}

Objective: to analyze the emergence and types of public policies which promote the development of cultural and creative industries in Jalisco, Mexico, with an impact on the Metropolitan Area of Guadalajara. Methodology: it is descriptive and proposes a typology for the analysis of public policies oriented towards the creative economy and their impacts. Results: there were found I5 government programs in which systemic policies stand out in the economic promotion. Among them are the Creative Digital City project and the supply policies through direct financing. The concentration and specialization in creative and cultural activities in Guadalajara and Zapopan have led to their recognition as creative territories, encouraging public supply-demand policies, and human capital training programs. Limitations: the information is insufficient to assess the impact of public policies in the municipalities. Value: research describes the way in which local public policies promote the development of the creative and cultural economy in the local space. Conclusions: the approach of public policies oriented to the creative economy has a structural and conjuncture background and imposes challenges to the provision and continuity of budgetary resources, entrepreneurial and innovative capacities development, and the creative communities' consolidation.

Keywords: public policy; creative economy; local development; Guadalajara; Zapopan; Jalisco.

Cómo citar: Lozano Uvario, K. M. (202I). Políticas públicas para una economía creativa en Jalisco y el área metropolitana de Guadalajara. región y sociedad, 33, el 375. doi: 10.22198/rys2021/33/1375

* Universidad de Guadalajara, Departamento de Geografía y Ordenación Territorial, Centro Universitario de Ciencias Sociales y Humanidades. Oporto Núm.939, Col. Autocinema, C. P. 44230, Guadalajara, Jalisco, México. Correo electrónico: katia.lozano@academicos.udg.mx; klozano@csh.udg.mx

Recibido: 11 de agosto de 2020

Reevaluado: 13 de enero de 2021

Aceptado: 5 de marzo de 2021

Liberado: 5 de abril de 2021

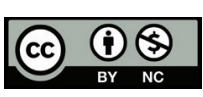




\section{Introducción}

La economía creativa (EC) plantea que la cultura es un factor de innovación, en cuyo centro se encuentra el proceso creativo como principal insumo (Palma y Aguado, 2010). Se asocia con la economía cultural porque trata de la producción, distribución y consumo de bienes y servicios culturales (Peters y Araya, 2010), y con la economía del conocimiento por su focalización en los beneficios económicos que producen las transacciones de bienes y servicios que tienen como propósito añadir valor económico intangible mediante el conocimiento, la innovación, el contenido creativo y la propiedad intelectual (PI) (Howkins, 2013; Peters y Araya, 2010; Conferencia de las Naciones Unidas sobre Comercio y Desarrollo [UNCTAD], 2008 y 2010; Valdivia López y Cuadrado-Roura, 2017).

Surgió de manera consecuente y asociada con la concepción de las industrias creativas que identificó en 1998 el Departamento de Cultura, Medios y Deportes del Reino Unido, en las que se incluyeron el mercado de arte y antigüedades, la publicidad, el software -incluido el de ocio interactivo-, la arquitectura, las artesanías, el diseño, el diseño de modas, la música, el cine, las artes escénicas, la televisión, la radio y las editoriales (Newbigin, 2017; Peters y Araya, 2010), a partir de las cuales se establece una articulación entre la economía y la cultura desde una visión instrumental (Szpilbarg y Saferstein, 2014). Por ende, la EC favoreció la transformación del enfoque no económico de los bienes culturales hacia uno en el que se comprenden como productos tangibles y servicios intelectuales o artísticos con contenido creativo, muy simbólico, que tiene objetivos de mercado y cuyo valor económico se produce a partir de recursos intangibles y mediante derechos irreductibles de PI como su característica común (Lash y Urry, 1998; Méndez, Michelini, Prada y Tébar, 2012; Szpilbarg y Saferstein, 2014). De ahí la ampliación de las industrias creativas hacia las actividades que orientan el mercado y la competencia, como las relacionadas con el diseño, la publicidad y el software.

Los gobiernos nacionales y subnacionales, entre ellos los latinoamericanos, y los organismos internacionales, como la Organización de las Naciones Unidas para la Educación, la Ciencia y la Cultura (UNESCO), UNCTAD y el Banco Interamericano de Desarrollo (BID), han planteado que la EC es estratégica. El proceso de institucionalización y legitimación que han realizado tiene el objetivo de reconocer que las industrias culturales y creativas (ICC) son fuente de empleo, impulsoras de contenido innovador, generadoras de valor y de exportaciones y un medio para el desarrollo del trabajo creativo (Buitrago Restrepo y Duque Márquez, 2013; Florida, 2012; Kong, 2014; Lazzeretti, Boix y Capone, 2012; Lazzeretti y Cinti, 2012; UNCTAD, 2008 y 2010). También han considerado que la EC es una vía para la rehabilitación y la regeneración de ciudades y regiones, por ser foco de atracción de turismo y de negocios (Caravaca Barroso, González Romero, Fernández Salinas y García García, 2013; Markusen y Gadwa, 2010; Méndez et al., 2012; Vila Seoane, 2017; Zarlenga, Rius-Ulldemolins y Rodríguez Morató, 2016). Debido a lo anterior, también se la relaciona con el fomento de 
políticas de promoción económica y como alternativa de desarrollo para tornar más atractivos y competitivos los territorios que sufren procesos de desindustrialización (Moeglin y Tremblay, 2013, p. 67).

Sin embargo, en la literatura académica han sido muy cuestionadas la imposición de las ICC en las agendas gubernamentales y la adopción de políticas públicas (PP) que pretenden crear oportunidades de desarrollo, sin un cuestionamiento de su alcance, o que son ambiguas en cuanto a quiénes forman parte de los trabajadores creativos o qué empresas deben identificarse como creativas. También se han cuestionado los límites entre los sectores que se involucran, o incluso el modo de abordar la creatividad (Boix y Lazzeretti, 2012; Greffe, 2017; Kong, 2014; Lazzeretti, Capone e Innocenti, 2017, p. 1696; Markusen, Wassall y Denatale, 2008; Szpilbarg y Saferstein, 2014; Tepper, 2002).

No obstante, persiste un gran interés en la EC en todos los niveles de gobierno -internacional, nacional y local-, evidente en una amplia variedad de informes e iniciativas relacionados con el término de ICC, que perciben a los sectores involucrados como parte de una nueva economía (Scott, 2017, p. 15). Al principio, las políticas locales relacionadas con la EC fueron parte de una estrategia de promoción económica o de apoyo a las industrias o actividades que producen conocimiento innovador y creativo (Hesmondhalgh y Pratt, 2005). Luego se dirigieron a los trabajadores y al establecimiento de lugares y comunidades creativas (Markusen y Gadwa, 2010, p. 9), con los cuales se espera aprovechar las oportunidades y conquistar mayores niveles de competitividad relacionados con el capitalismo cognitivo, la cultura y la creatividad.

En este contexto cabe preguntarse, ¿los gobiernos, en sus distintos niveles, mantienen una postura hegemónica sobre el reconocimiento de las ICC, o se han adaptado y particularizado según las características territoriales? ¿Qué tipo de políticas implementan? ¿Son generales o se dirigen a algún sector en particular? ¿Qué efectos propician? ¿Se mantienen en la promoción económica, o han pasado a implementar políticas de aliento al trabajo creativo, a la formación de comunidades o lugares creativos o integrales?

El objetivo de este trabajo es analizar las condiciones en que emergen las PP e identificar qué tipo se relaciona con la construcción de una EC desde el enfoque del desarrollo local para vincular dichas condiciones con el aprovechamiento de los recursos culturales, creativos y del conocimiento. Se analiza el caso de Jalisco y el de los municipios centrales del área metropolitana de Guadalajara (AMG), donde se concentran las empresas identificadas en las ICC. También es importante identificar las acciones públicas del gobierno estatal y de los gobiernos municipales que han delineado las políticas y los programas económicos que coadyuvan al desarrollo de la entidad en el último decenio.

Desde este punto de vista, se asume una relación entre la cultura, la economía y el territorio a partir de la política pública, la cual estaría alentando en un primer momento la localización y el crecimiento de actividades relacionadas con las ICC, la activación de recursos intangibles y los efectos territoriales que se producen en los espacios donde se ubican y los que se crean debido a las interrelaciones establecidas en el lugar, vinculadas con la proximidad. 
En consecuencia, en este documento se utiliza una metodología de tipo descriptivo: el análisis propone la utilización de una tipología para identificar y clasificar las PP estatales y municipales a partir del reconocimiento en sus objetivos de áreas de intervención, población objetivo y su orientación hacia la economía. Se elige como caso el estado de Jalisco y los municipios del AMG. Además, se consideró su impacto en el territorio a través de los presupuestos asignados y de los beneficiarios de dichas políticas. Para ello, se utilizó la información y los datos recolectados a través de investigación en fuentes primarias, en las bases públicas del gobierno del estado de Jalisco y de los gobiernos de los municipios investigados, así como en sus respectivos presupuestos de egresos y los informes de gobierno de 2013 a 2019.

El documento integra tres apartados: en el primero se presentan los fundamentos y la metodología propuesta para el análisis de las PP orientadas a la EC; el segundo, muestra los resultados correspondientes al estado y al AMG. Por último, la tercera parte son las conclusiones, dirigidas a reflexionar sobre las pautas que estas políticas están propiciando para el desarrollo económico de la entidad, los elementos que lo limitan, los que constituyen un desafío y aquellos que pueden contribuir a una mayor y mejor incidencia para el beneficio y el bienestar local.

\section{Las políticas públicas y su orientación a la economía creativa: fundamentos y metodología de identificación}

El enfoque del desarrollo local considera que la administración gubernamental es el actor principal de la ejecución de las PP, aun cuando su gestión supone también la descentralización, operada a través de organizaciones intermedias que prestan servicios reales, financieros o ambos a las empresas y a las organizaciones y que promueven la mejora competitiva de los sistemas productivos y de la calidad de vida de la sociedad (Vázquez Barquero, 2000, p. 105).

Las PP se entienden como construcciones sociales concretas, contingentes, en las que participan múltiples agentes, pero el Estado es su principal responsable, aunque no de manera exclusiva ni excluyente, a través de un gobierno y la administración pública (Graglia, 2014, pp. 50-51). En ellas se impone un sistema de acción en un sector de la sociedad, ordenado por un conjunto de operaciones con determinadas orientaciones valorativas y con la asignación de recursos para el cumplimiento de objetivos y metas, en forma de planes, programas y proyectos (Hernández Barba, 2009, pp. 44-45), con el fin de resolver de manera puntual un problema definido de forma política como colectivo, en el interés de los grupos sociales (beneficiarios) (Knoepfel, Larrue, Varone y Dieck, 2007, p. 12). En este sentido, la política pública es un proceso de complejas resoluciones en las que resulta imperativo entender cómo los gobiernos definen y determinan las demandas de interés público y cómo forman su agenda (Aguilar Villanueva, 1993, p. 10). 


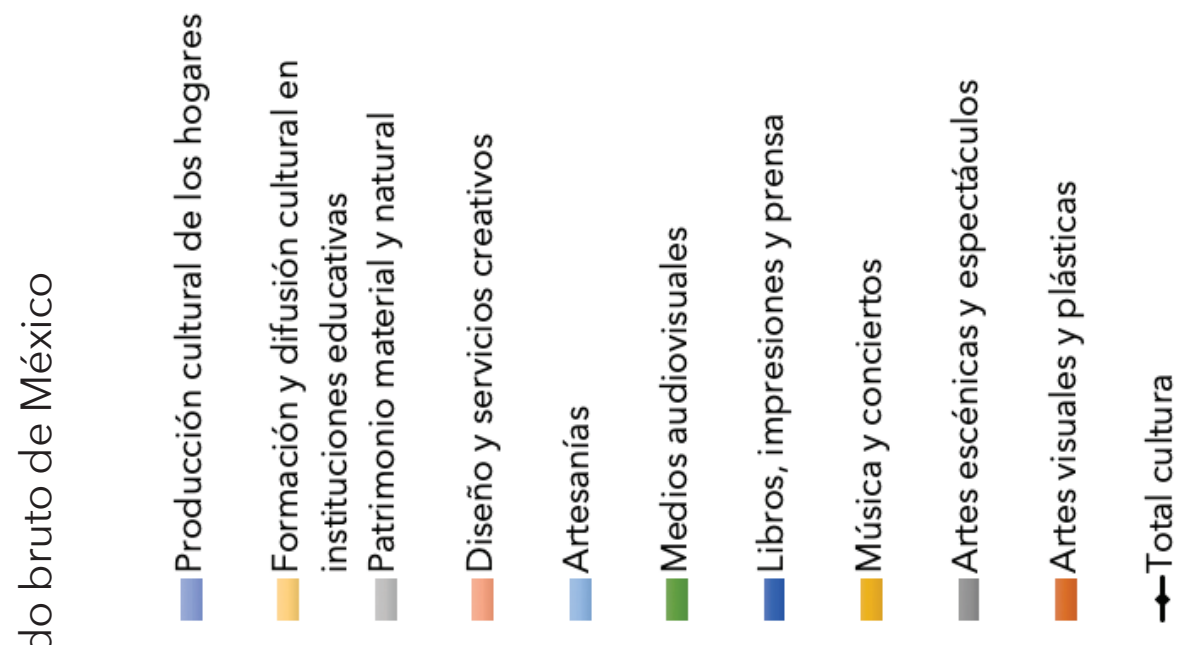

0
0
0
0
0

(8)

万ั

ㅎำ

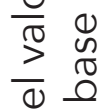

बำ 듬

ब)

营

w

O

중

늘

is

ए)

O

:은

$\frac{0}{0}$

$\frac{2}{\underline{U}}$

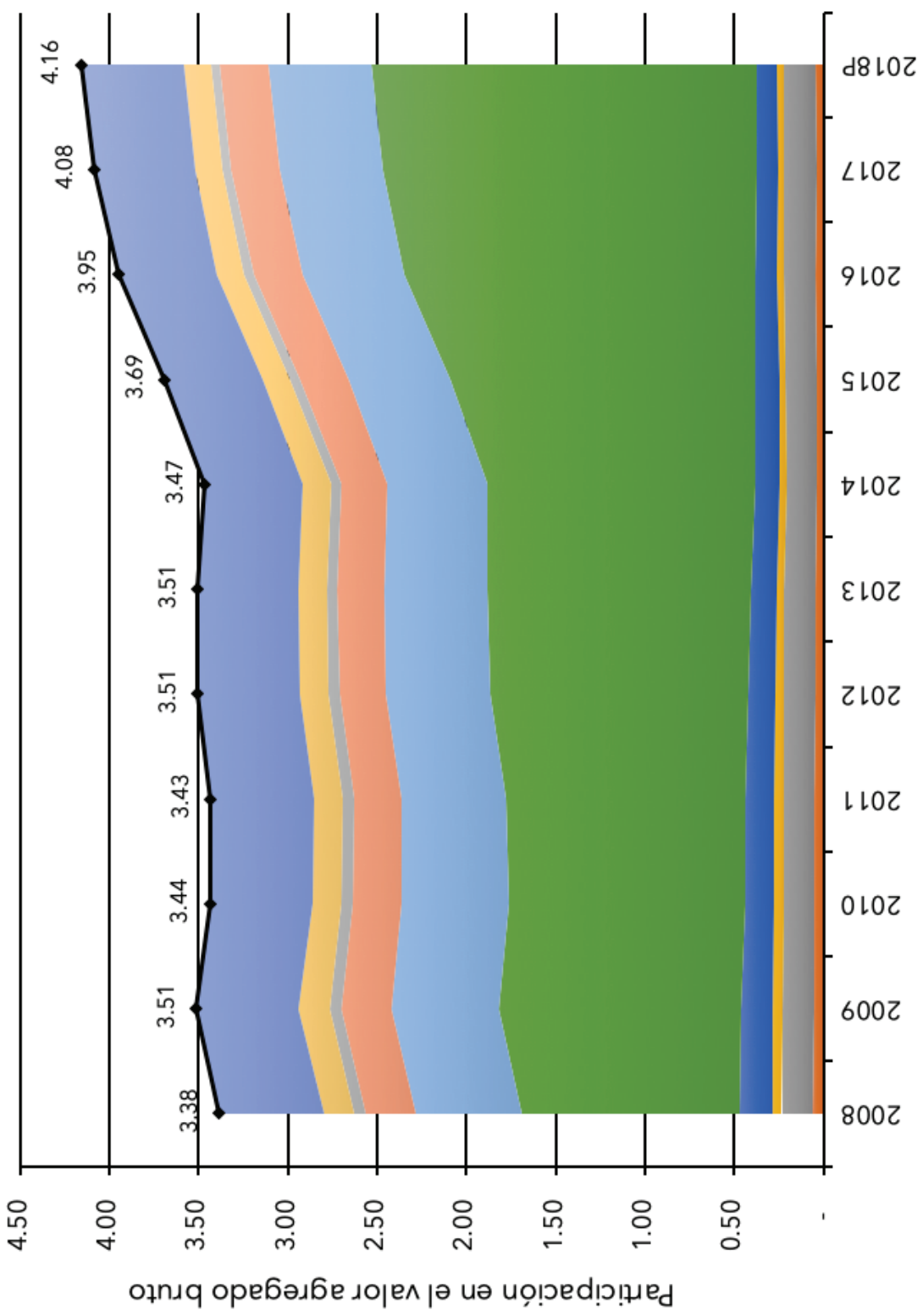

d8102

$\angle 102$

102

102

102

$\varepsilon 102$

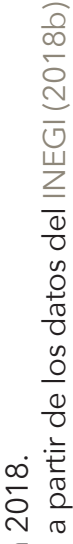

$\stackrel{+}{\circ}$

이ํ

辻 
En el caso de la EC y su orientación a las ICC, las estrategias y políticas han sido alentadas por el reconocimiento de la cultura, el conocimiento y la creatividad como recursos específicos, difíciles de deslocalizar, con capacidad de producir riqueza e impulsar procesos de desarrollo territorial (Caravaca Barroso et al., 2013, p. 82), dada su importancia creciente en el producto interno bruto (PIB) (Programa de las Naciones Unidas para el Desarrollo [PNUD] y UNESCO, 2014; Toussaint Alcaraz, 2013). Por ende, "la cultura se ha vuelto un instrumento para intentar el desarrollo económico [...] generar empleos [...] favoreciendo, por ejemplo, la instalación de nuevas empresas (Benhamou, 2009, p. 16)".

Así, por ejemplo, Negrete (2013) apunta que en México las ICC fueron consideradas un factor de desarrollo a escala nacional a partir del periodo de gobierno 2006-2012, en el que se las reconoció como generadoras de riqueza y de desarrollo colectivo, al impulsar el empleo, los ingresos, la cohesión social, la mejora en la calidad de vida y el apoyo en la reducción de la violencia y las adicciones, a diferencia de los periodos anteriores en los que la cultura se estimaba un pasivo para las finanzas públicas, cuyo único promotor era el Estado (Negrete, 2013, pp. 248-249), financiador de las actividades de fomento y conservación del sector cultural (Piedras, 2006, p. 40).

Este cambio de visión en la política del país, asociando la cultura y la economía, se reflejó en 2014 con la publicación de la Cuenta Satélite de la Cultura, a partir de la cual se cuantifican a escala nacional los flujos económicos que producen las actividades creativas y culturales, ${ }^{1}$ cuyos resultados estiman incrementos paulatinos en el PIB, que pasa de 3.38\% en 2008 -su primer año de medición- a 4.16\% en 2018, a precios de 2013 (Instituto Nacional de Estadística y Geografía [INEGI], 2018b), sobre todo en las actividades de los medios audiovisuales, las artesanías, el diseño y los servicios creativos, según se muestra en la figura 1.

Por otra parte, cuando se define la cultura como un sector importante para la economía de un país, también se reconoce la necesidad de establecer nuevas formas de acercamiento entre la cultura y los negocios, a fin de obtener mayores beneficios a partir de la transformación de sus estructuras productivas, de las formas de distribución y consumo, al aumentar la demanda de digitalización, de uso de tecnologías de la información y comunicación avanzadas, de tecnología de punta, de requerimientos de PI, e incluso a partir de la movilidad laboral (Benavente y Grazzi, 2017; Toussaint Alcaraz, 2013). De ahí que el papel de los agentes públicos resulte esencial para dinamizar el entramado socioeconómico de los territorios con el objeto de reforzar las ventajas competitivas, aprovechar los recursos propios y lograr una mejor inserción global (Caravaca Barroso et al., 2013, p. 88).

Así mismo, uno de los fundamentos que propicia la intervención gubernamental en relación con las ICC, radica en la identificación de fallas de mercado

1 El Sistema de Cuentas Nacionales de México considera en la medición de la Cuenta Satélite de la Cultura las siguientes áreas generales: a) artes visuales y plásticas; b) artes escénicas y espectáculos; c) música y conciertos; d) libros, impresiones y prensa; e) medios audiovisuales; f) artesanías; g) diseño y servicios creativos; h) patrimonio material y cultural; i) formación y difusión cultural en instituciones educativas; y j) producción cultural de los hogares (INEGI, 2013, pp. 238-239). 
y de coordinación, asociadas con las características de los bienes y servicios culturales y creativos, los cuales tienen un comportamiento mixto, ya sea como bienes privados o como públicos (Throsby, 2000, pp. 23, 140). Esto es, mientras en el mercado se caracterizan con un cierto grado de no rivalidad - sin sustitutos cercanos-, su parte pública incluye el principio de no exclusión al consumo (todos tienen derecho a estos bienes y servicios), con estructuras de costo complejas y distintas entre sí, incluso con altos costos hundidos, que pueden crear barreras de ingreso, concentración de mercado e ineficiencias asociadas con la información incompleta, que propician que el sistema de precios tenga un funcionamiento incorrecto. Por otra parte, es probable que generen externalidades positivas de conocimiento, producto y red (Alonso Hierro y Martín Fernández, 2013; Benavente y Grazzi, 2017), por lo cual la creación de políticas y la acción gubernamental resultan centrales en la corrección de dichas fallas y en la promoción estratégica de su desarrollo.

Se esperaría que la construcción de una EC que promueva el desarrollo local involucre no sólo resultados en el ámbito económico, como la creación de empleo en los sectores definidos como creativos y culturales, la formación de nuevas empresas, el incremento de la innovación y el registro de PI, sino que también relacione acciones en lo político-administrativo y en lo socioterritorial, tales como la construcción de redes, las alianzas público-privadas, un marco normativo, el aliento a la participación de la sociedad civil o el reforzamiento de la identidad y de los valores culturales locales, en la construcción de comunidades y lugares creativos, entre otros.

Al respecto, la UNESCO (2010, p. 15) especifica, en lo que se refiere a las políticas de fomento de las ICC, seis áreas de intervención: 1) la competitividad e innovación, 2) los recursos humanos y la formación, 3) la infraestructura y las inversiones, 4) el desarrollo de mercados, 5) el marco normativo y 6) la financiación. Estas áreas permiten establecer las modalidades de intervención, las decisiones y las acciones, así como los grupos-objetivo a los que se puede orientar la política pública (Knoepfel et al., 2007).

Del mismo modo, con el objetivo de resolver las fallas del mercado y las de coordinación, así como las formas de competencia, para crear las condiciones de eficiencia con intervenciones específicas, Benavente y Grazzi (2017) puntualizan cuatro tipos de política: 1) de oferta, a través del otorgamiento de financiamiento directo (subvenciones, subsidios u otro tipo de asistencia financiera) e indirecto (regímenes tributarios especiales o exenciones tributarias); 2) de demanda, en el que se consideran los apoyos para incentivar el consumo de bienes y servicios culturales y creativos; 3 ) de formación de capital humano, con el que se busca resolver fallas de coordinación entre la demanda de habilidades de la economía creativa y el sistema educativo, promoviendo la creación de fuerza laboral creativa y el fortalecimiento de capacidades de investigación; y 4) sistémica, orientada a corregir las fallas de coordinación y la incertidumbre que provoca la naturaleza intangible del contenido creativo. En este tipo se incluyen las políticas de clúster.

En relación con la fase de evaluación, en la cual se observa el impacto de las PP orientadas a la EC, Sánchez Gardey (2014) define que éste puede ser de tres 
tipos: 1) directo, a partir de los incrementos provocados en la demanda de las empresas locales, o por los presupuestos asignados o los gastos ejercidos tanto en el desarrollo de actividades, como en los gastos de los demandantes; 2) indirecto, derivado del incremento de la actividad en las empresas del entorno local; y 3) inducido, el que potencia la capacidad futura de compra, diferido en el tiempo y condicionado por los hábitos de ahorro y de compra de los consumidores, tales como los pagos directos al personal contratado.

Puesto que las PP pueden ser reconocidas en su diseño, por el objetivo por el que fueron creadas; en su implementación, por las modalidades de apoyo que generan, así como por las áreas en donde intervienen, se utilizó una tipología para el análisis de los programas públicos en el estado de Jalisco durante el periodo de 2013 a 2020, tomando como base de su integración la propuesta de Benavente y Grazzi (2017) y relacionando en cada tipo las áreas de intervención que especifica la UNESCO (2010), ya que la revisión de unas y otras permite su asociación (véase figura 2).

Figura 2. Tipología de las políticas públicas relacionadas con la economía creativa

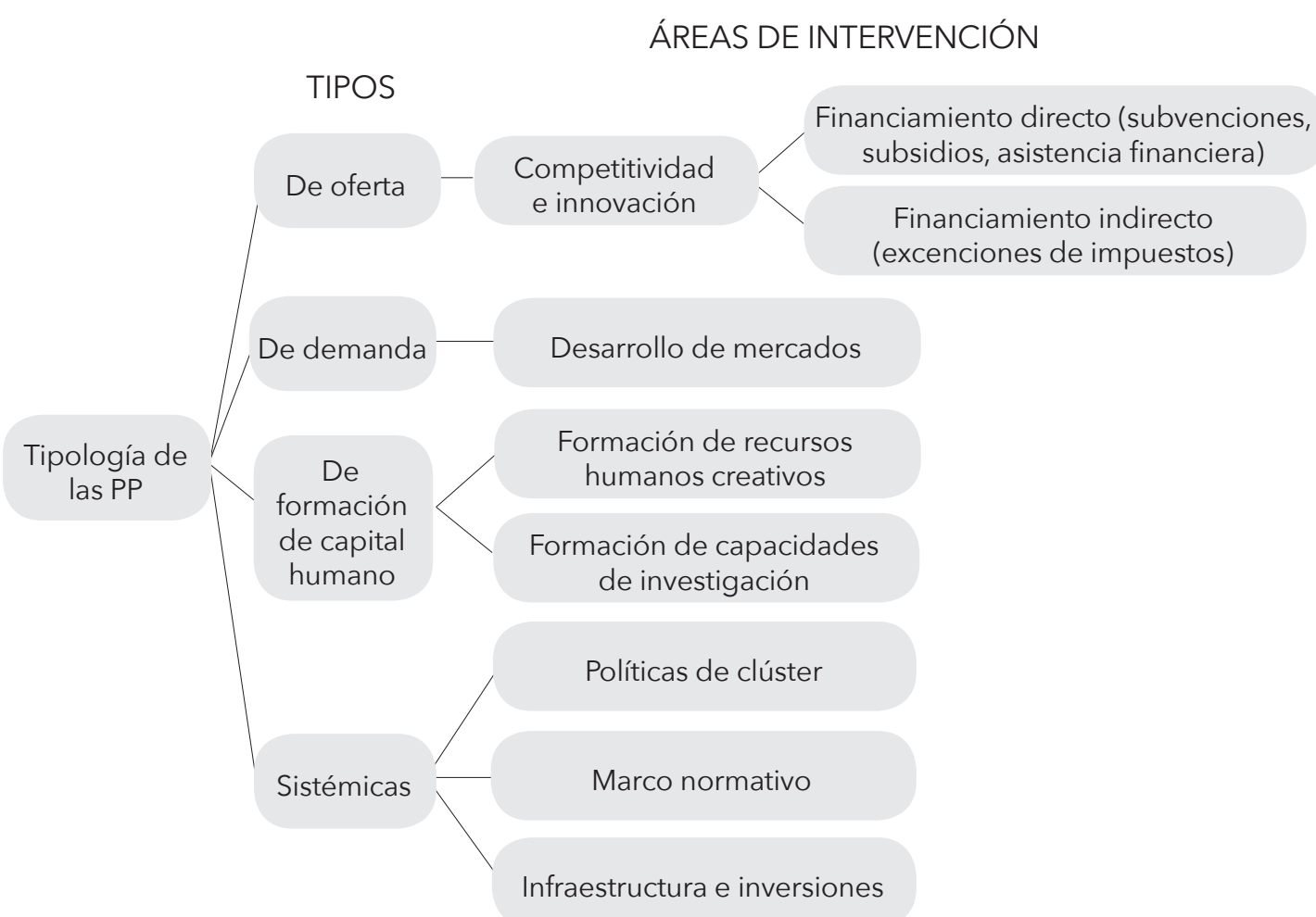

Fuente: elaboración propia a partir de datos de la UNESCO (2010) y de Benavente y Grazzi (2017). 
En el análisis y la selección de los programas públicos se identificó su temporalidad, su objetivo y su asociación con el desarrollo económico de la cultura, la creatividad y el conocimiento. También se determinó la población-objetivo a la que se dirigieron, utilizando la información procedente del sistema de monitoreo de la Secretaría de Planeación y Participación Ciudadana del Gobierno de Jalisco y los informes del Ejecutivo estatal.

El análisis se complementó con la identificación, en las mismas fuentes de información, de los tipos de impacto de las políticas culturales y creativas, siguiendo las ideas que propone Sánchez Gardey (2014), a partir del presupuesto ejercido y del número de beneficiarios que se documenta en los presupuestos gubernamentales y en el ejercicio anual estatal, para cada uno de los programas seleccionados.

También se indagó en las bases de datos abiertas de los gobiernos municipales, siguiendo el mismo criterio, aun cuando los resultados fueran limitados por no contar con la suficiente claridad y transparencia para identificar los programas, los recursos y los beneficiarios, tales como los reportados en el análisis estatal.

De manera complementaria, se realizó investigación documental sobre el desarrollo de la estructura económica de Jalisco para conocer el contexto económico en el que se promueven las políticas, los sectores estratégicos y los niveles territoriales (estatal y municipal) que se privilegian, con el objetivo de dimensionar y explicar la construcción de este sistema de acción.

\section{Resultados del análisis de las políticas públicas orientadas a la economía creativa en Jalisco y el AMG}

A lo largo de la historia, la vida económica de Jalisco ha sido definida por el desarrollo del municipio de Guadalajara, sólo en las últimas décadas se incluyó a los municipios que integran su área metropolitana, ${ }^{2}$ los cuales en conjunto concentraron en promedio, entre 2004 y 2014, 60.2\% de las unidades económicas, $73.8 \%$ de la población ocupada y $81.95 \%$ del valor agregado censal bruto de la entidad (INEGI, 2014).

El aparato productivo del AMG se orientó desde la década de 1990 hacia los mercados nacional e internacional, al convertirse en el tercer destino no fronterizo con instalación de maquiladoras de alta exportación y el quinto receptor más importante de inversión extranjera de todo el país (Arroyo Alejandre, 1993, p. 97; Woo Gómez, 2003, p. 56): concentró en 87.7\% el complejo de alta tecnología de Jalisco, sobre todo en la industria electrónica (Palacios Lara, 2008, pp. 24-27).

2 Los municipios de Guadalajara, Zapopan, Tlaquepaque y Tonalá han integrado desde 1980 la primera corona metropolitana, mientras que en 2005 la conurbación demográfica asoció una segunda con Tlajomulco de Zúñiga, El Salto, Juanacatlán e Ixtlahuacán de los Membrillos, los cuales en conjunto fueron declarados como AMG en el Periódico Oficial de Jalisco en diciembre de 2009 (Arellano Ríos, 2013, p. 83). 
No obstante, debido al crecimiento urbano y a un proceso de descentralización industrial, a partir del cual los establecimientos industriales se dispersaron, la metrópoli -sobre todo Guadalajara como su mayor centralidad económica-, finalizó el siglo XX con actividades comerciales y de servicios de manera preponderante, tales como las asociadas a las funciones de diseño, programación, y mercadotecnia, así como de servicios corporativos (Arias, 1993), además de los influjos de capitales externos a la región y los internacionales en dichos sectores (Arroyo Alejandre, 1993, p. 112).

La especialización estatal en la industria de alta tecnología y en dos áreas del conocimiento -tecnologías de información, microelectrónica y multimedia, así como en la biotecnología (Consejo Estatal de Ciencia y Tecnología de Jalisco, 2003)- generó en los subsectores del 333 al 336 fabricación de maquinaria y equipo, equipo de computación, comunicación, medición y de otros equipos, componentes y accesorios electrónicos, fabricación de accesorios, aparatos eléctricos y equipo, un PIB de entre 6.41 y $9.29 \%$ en el periodo 2003-2018 (INEGI, 2018a).

Este crecimiento económico se ha producido en conjunto con la construcción de un sistema regional de innovación asociado con las PP y los fondos que impulsaron los negocios basados en el conocimiento, el aprendizaje colectivo y la disposición a compartir información y conocimientos de utilidad común que facilitaron y propiciaron la creación de alianzas entre los sectores público y privado, así como la vinculación entre el gobierno local, las empresas y las instituciones educativas de nivel superior radicadas en la entidad (Arechavala, Rico, Rodríguez y Huerta, 2010, p. 197; Basulto Castillo, Hernández Pérez y López Méndez, 2016; Palacios Lara, 2008, pp. 33-34).

La producción de software y la prestación de servicios computacionales pueden incluirse dentro de las empresas creativas, porque están centradas en los sectores de alta tecnología y porque las PP las promueven y utilizan los fondos financieros que impulsan los negocios basados en el conocimiento (Ordóñez, 2017). El éxito económico de estos dos tipos de empresas alentó que el gobierno del estado, durante el sexenio 2013-2018, estableciera una política explícita en relación con el fomento de las ICC, a partir de que la cultura -incluida en ella la creatividad - se asumiera como parte integral de las estrategias de desarrollo económico, social y político de la entidad, considerándose un sector estratégico de crecimiento completo de la sociedad. La Secretaría de Cultura de Jalisco (SCJ), creada en 1992, ha operado esta política y es la responsable de coordinar y articular el desarrollo de las capacidades creativas y productivas (SCJ, 2018), estableciendo, incluso como parte de su estructura operativa, la Dirección de Industrias Creativas con el propósito de "fomentar la creación de bienes y servicios culturales, como herramienta de desarrollo económico para mejorar la calidad de vida de los artistas y creadores, y fortalecer, al mismo tiempo, las iniciativas de la sociedad civil" (Gobierno del Estado de Jalisco, 2013).

No obstante, si bien con la creación de dicha Dirección se proyectaron los objetivos económicos estatales para las ICC durante el sexenio 2013-2018, la identificación por sectores, ramas o clases de actividad permaneció sin especificación propia y se orientó siguiendo las experiencias que el Reino Unido había 
reconocido (Universidad de Guadalajara, 2015). Fue en 2019 cuando se reportó la existencia de 6764 establecimientos y de 52484 empleados, siguiendo la clasificación propuesta por el Centro de Cultura Digital, el British Council y el BID, en nueve grupos de actividad económica: 1) música y artes interpretativas, 2) editorial, 3) publicidad y marketing; 4) arquitectura; 5) artesanía; 6) librerías y museos; 7) software; 8) cine, radio y televisión; y 9) diseño. Estos grupos participaron con $7.4 \%$ del total de las unidades económicas y con $7.2 \%$ del empleo nacional, produciendo entre 2015 y 2018 un crecimiento de $5.38 \%$, en contraste con todos los sectores del estado que aumentaron tan sólo 3.62\% (Centro de Cultura Digital et al., 2019). En relación con ello, la figura 3 presenta el mapa

Figura 3. Localización de las unidades económicas de las ICC en Jalisco

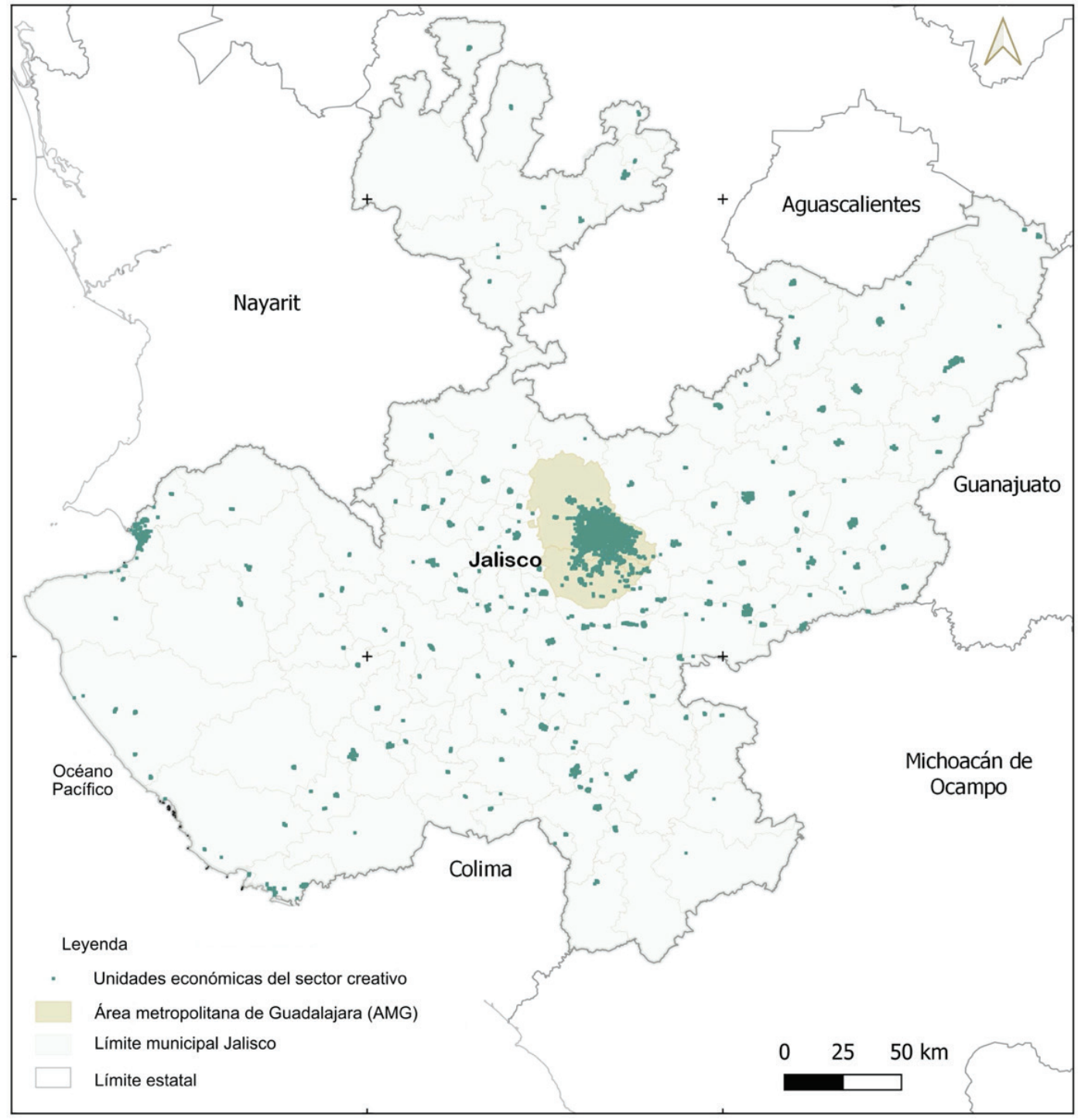

Fuente: elaboración propia a partir del INEGI (2020). 
de localización de las ICC en Jalisco a partir de los datos del Directorio Estadístico Nacional de Unidades Económicas (DENUE) al mes de abril de 2020, donde se aprecia la concentración de dichas actividades en el AMG, con 3659 empresas.

En específico, las tres estrategias de desarrollo económico de las ICC expuestas en el Programa Estatal de Cultura 2013-2018 se vinculan con el desarrollo empresarial de las actividades concentradas en el AMG, con la descentralización y con el fortalecimiento financiero de los municipios no metropolitanos. Dichas estrategias se describen a continuación (SCJ, 2018):

1. La creación de capacidades institucionales municipales a partir del funcionamiento del Fondo Estatal de Infraestructura Cultural y del Fondo Jalisco de Animación Cultural.

2. El impulso del programa Rutas Creativas y Estrategias para el Desarrollo Regional, focalizado en desarrollar el capital creativo y patrimonial de las regiones de Jalisco que cuentan con vías férreas en desuso, tal como la región Valles, cuyo fomento se asoció con el sistema de rutas culturales (Paisaje Agavero, Ruta del Peregrino y la arqueológica-cultural Guachimontones). El programa orientó no sólo el empleo de estos recursos, sino también la gestión del binomio turismo-cultura, mediante proyectos en asociaciones público-privadas, en áreas rurales o en municipios no metropolitanos (Lozano Uvario, Méndez Guardado y González Torreros, 2018).

3. El fortalecimiento del desarrollo empresarial en el sector cultural y creativo mediante instrumentos financieros apropiados, herramientas para la formación empresarial, asesoría y apoyo para la creación de empresas creativas, clústeres e incubadoras, así como el fomento de la cultura de la asociatividad que contribuya a la creación de redes para alentar la oferta de bienes y servicios culturales, a la par de la mejora en la calidad de vida de los artistas y los creadores.

Con base en estas estrategias, se encontraron en las bases de datos gubernamentales 15 programas públicos con incidencia en el AMG, ${ }^{3}$ implementados por el gobierno del estado a través de cuatro organismos gubernamentales. La SCJ es la dependencia que lidera $60 \%$ de ellos. Los resultados de la clasificación según los tipos de políticas definidas en la metodología se presentan en la tabla 1.

Con respecto al impacto de dichos programas, los resultados sobre el presupuesto asignado en el estado entre 2013 y 2020 evidencian, por una parte, la prioridad que tienen las políticas sistémicas: $50.1 \%$ en las cuales se incluye el proyecto Ciudad Creativa Digital (CCD); las de oferta a través del financiamiento directo, 36.3\%; las de formación de capital humano, 10.2\% y las de demanda, 3.4\% (véase tabla 2).

3 La revisión de las políticas y de los resultados de la estrategia Rutas Creativas y Estrategias para el Desarrollo Regional se puede consultar en Lozano, Méndez y Castañeda (2018). 
Lozano Uvario

\begin{tabular}{|c|c|c|c|c|c|c|}
\hline $\begin{array}{l}0 \\
0 \\
\frac{0}{0} \\
0 \\
0 \\
0 \\
0 \\
\frac{0}{0} \\
\frac{\pi}{0} \\
\frac{0}{0} \\
\frac{0}{0} \\
\frac{0}{0} \\
\Sigma\end{array}$ & & 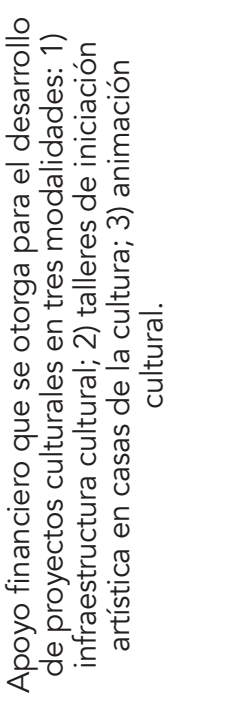 & 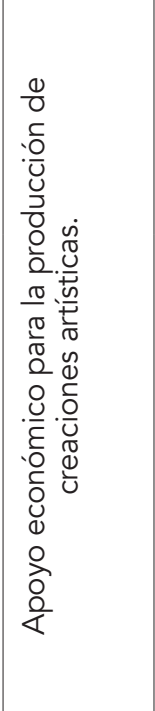 & 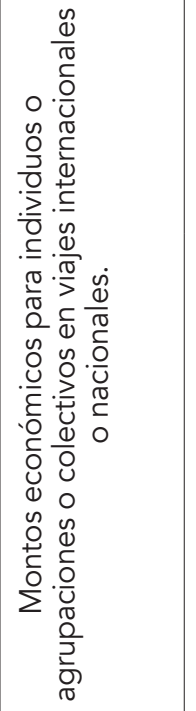 & 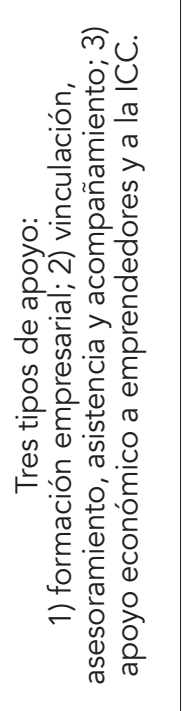 & 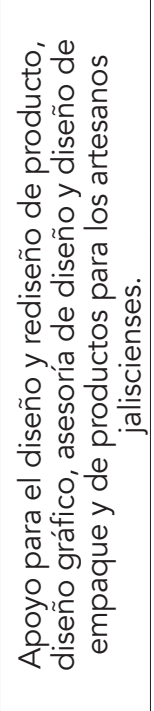 \\
\hline 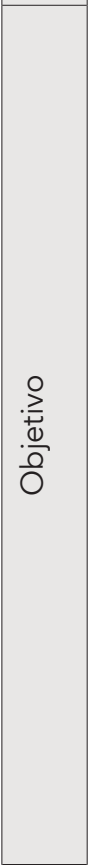 & 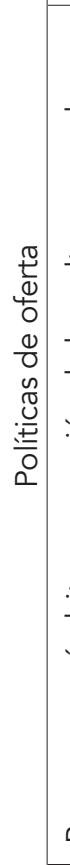 & 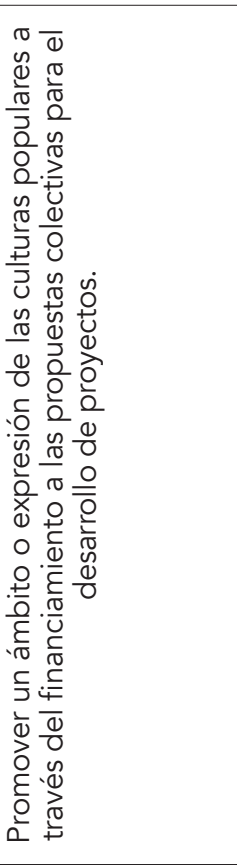 & 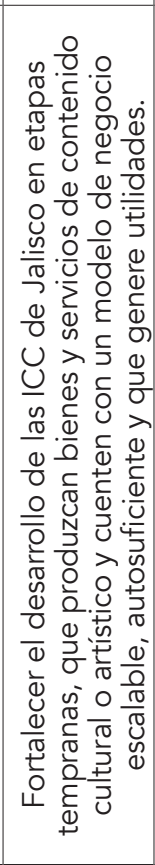 & 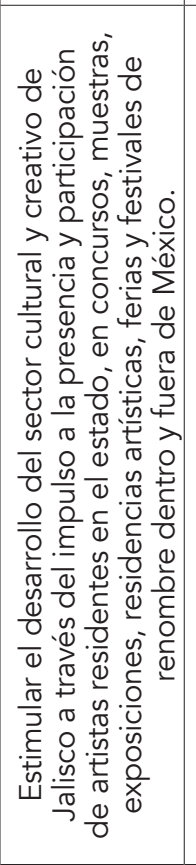 & 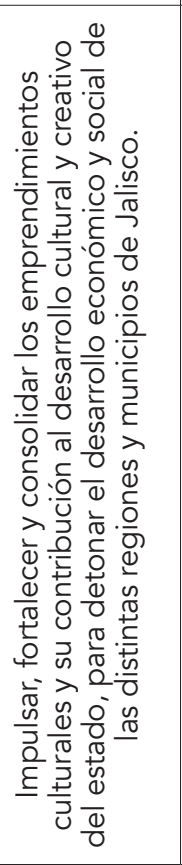 & 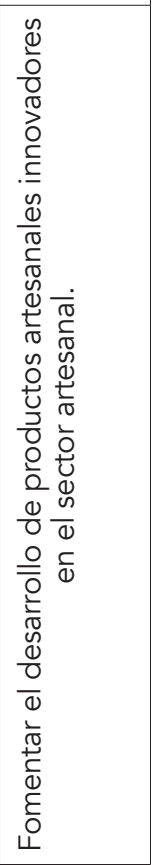 \\
\hline 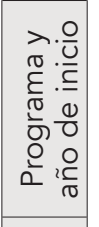 & & 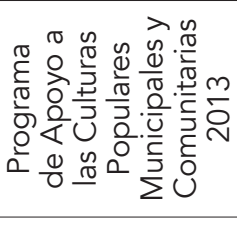 & 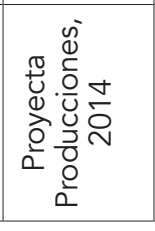 & 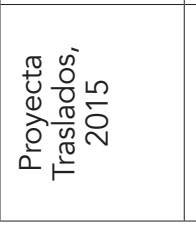 & 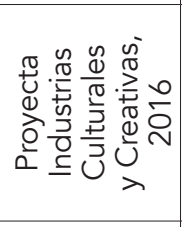 & 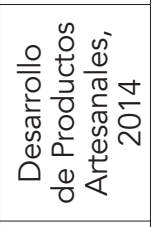 \\
\hline$\left|\begin{array}{ll}0 & 0 \\
0 \\
\frac{\pi}{0} & 0 \\
0 & \frac{1}{0} \\
\frac{0}{0} & \frac{0}{0} \\
0 & 0 \\
\overline{0} & 0 \\
0 & 0 \\
0 & 0 \\
0\end{array}\right|$ & & 己 & & & & 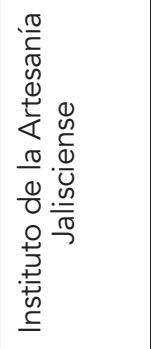 \\
\hline
\end{tabular}




\begin{tabular}{|c|c|c|c|}
\hline 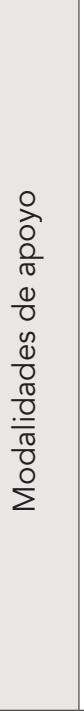 & 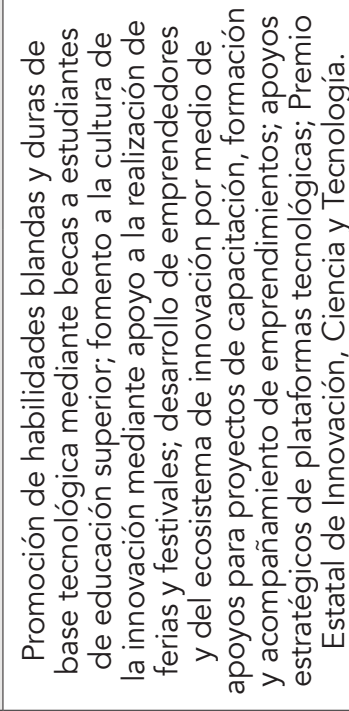 & 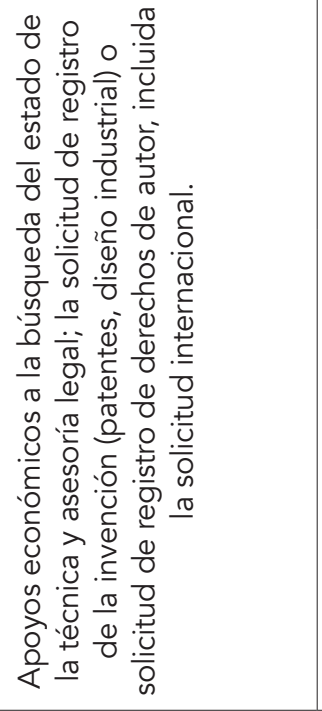 & 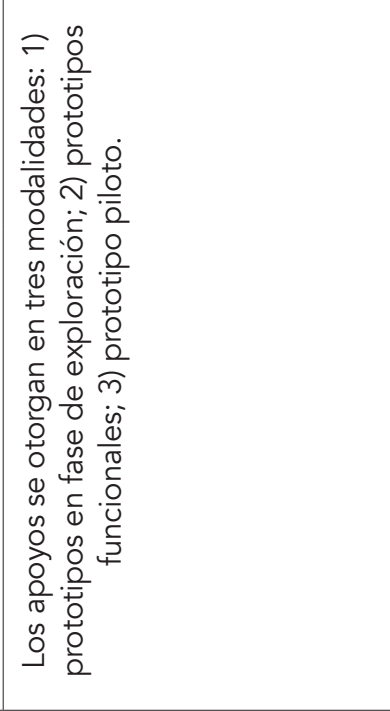 \\
\hline$\frac{\stackrel{0}{+}}{\frac{0}{0}}$ & 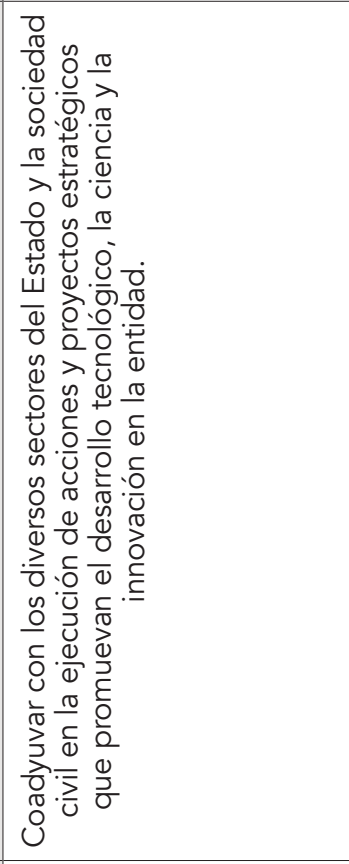 & 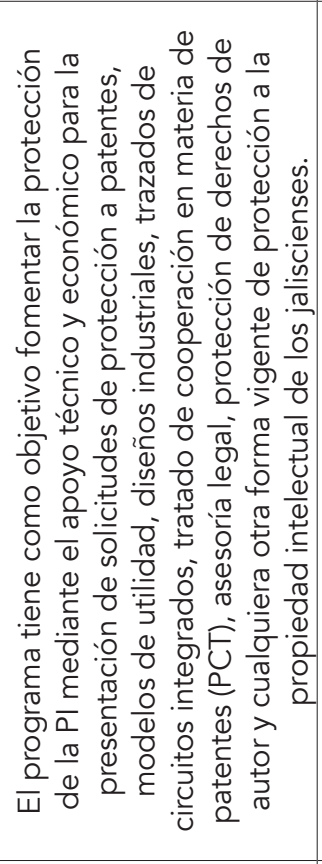 & 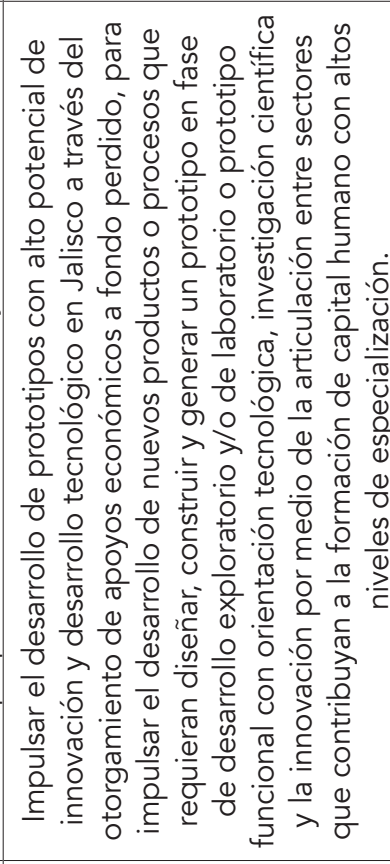 \\
\hline 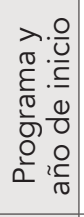 & 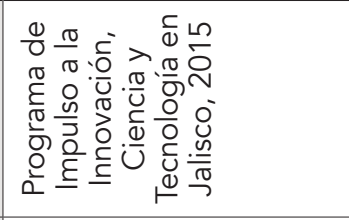 & 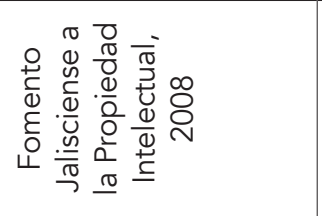 & 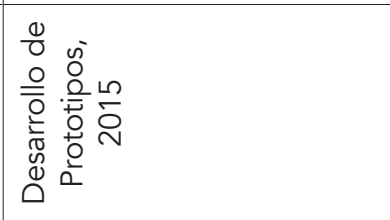 \\
\hline 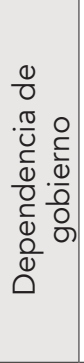 & 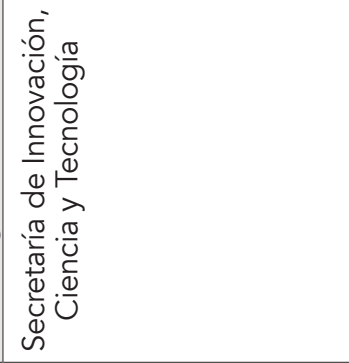 & \multicolumn{2}{|l|}{ 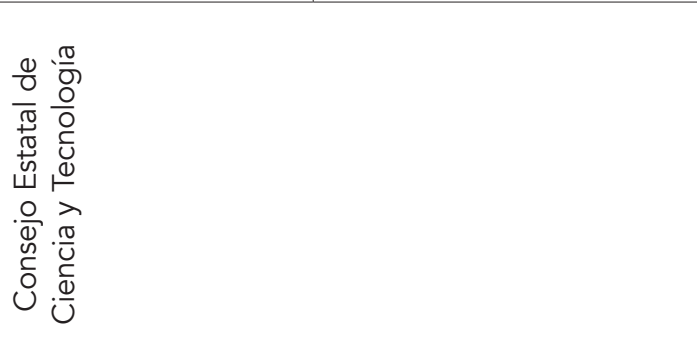 } \\
\hline
\end{tabular}


Lozano Uvario

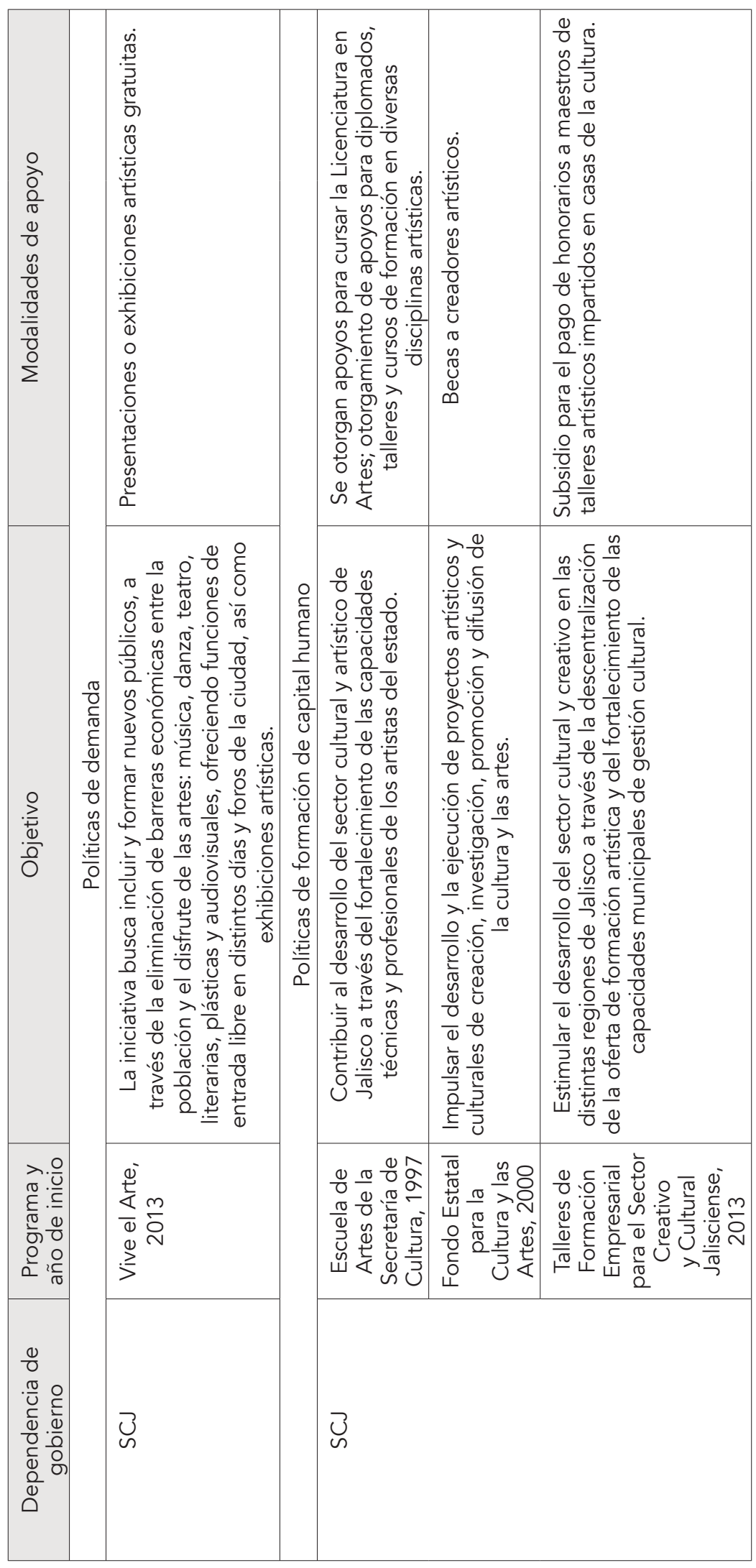




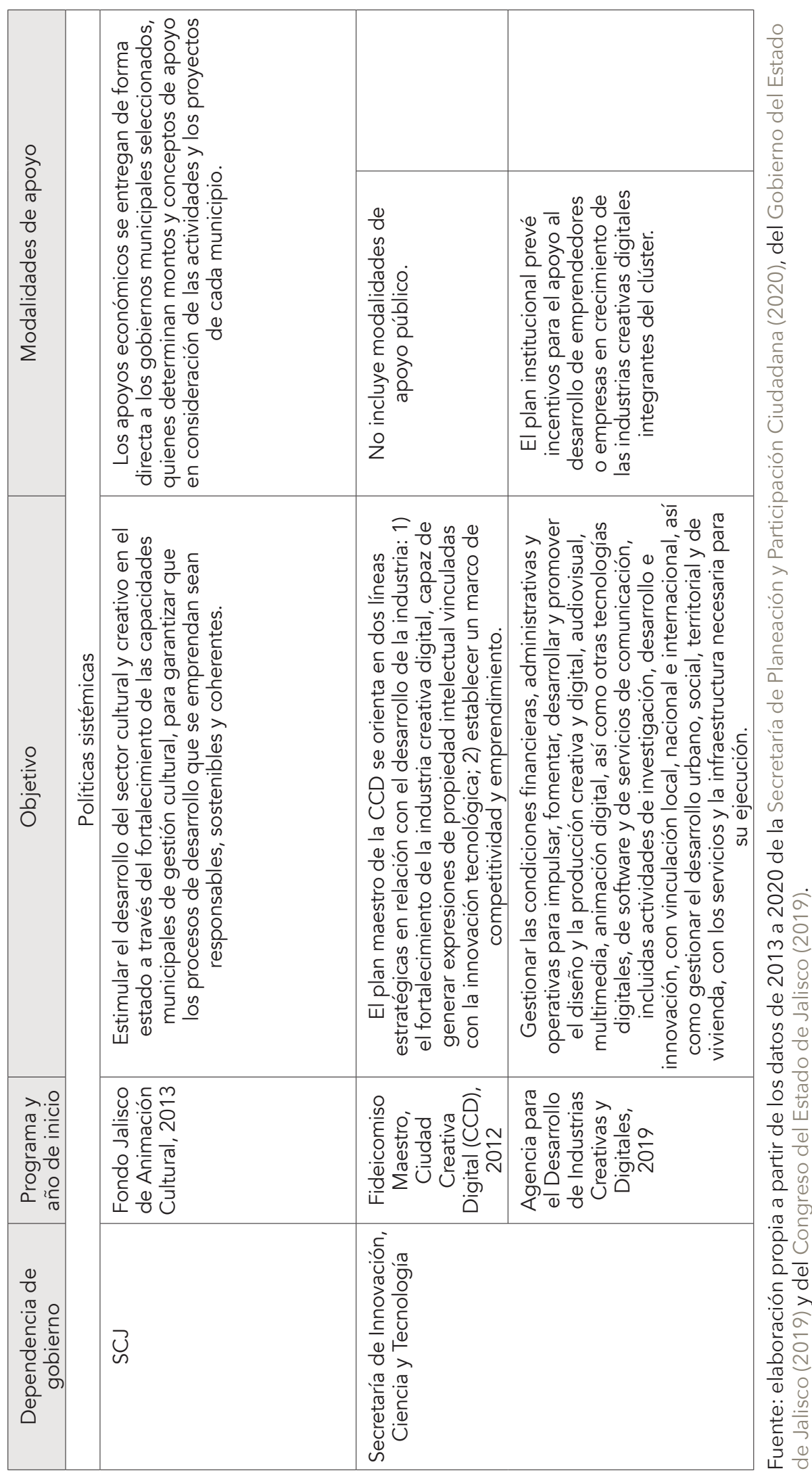


Tabla 2. Presupuesto asignado por el gobierno de Jalisco según el tipo de PP en el periodo 2013-2020 (miles de pesos corrientes)

\begin{tabular}{|c|r|r|r|r|r|}
\hline \multirow{2}{*}{ Año } & \multicolumn{5}{|c|}{ Tipo de política pública } \\
\cline { 2 - 6 } & De oferta & De demanda & $\begin{array}{c}\text { De formación de } \\
\text { capital humano }\end{array}$ & Sistémicas & Total por año \\
\hline 2013 & $\$ 1000$ & $\$ 0$ & $\$ 0$ & $\$ 0$ & $\$ 1000$ \\
\hline 2014 & $\$ 50117$ & $\$ 6006$ & $\$ 0$ & $\$ 100000$ & $\$ 156122$ \\
\hline 2015 & $\$ 53011$ & $\$ 0$ & $\$ 19707$ & $\$ 36043$ & $\$ 108762$ \\
\hline 2016 & $\$ 25811$ & $\$ 14307$ & $\$ 19210$ & $\$ 44165$ & $\$ 103494$ \\
\hline 2017 & $\$ 28405$ & $\$ 3844$ & $\$ 20157$ & $\$ 53305$ & $\$ 105710$ \\
\hline 2018 & $\$ 39553$ & $\$ 3765$ & $\$ 19621$ & $\$ 47165$ & $\$ 110106$ \\
\hline 2019 & $\$ 54268$ & $\$ 0$ & $\$ 2500$ & $\$ 60784$ & $\$ 117552$ \\
\hline 2020 & $\$ 44535$ & $\$ 0$ & $\$ 2500$ & $\$ 68251$ & $\$ 115286$ \\
\hline $\begin{array}{c}\text { Total } \\
\text { acumulado }\end{array}$ & $\$ 296701$ & $\$ 27921$ & $\$ 83696$ & $\$ 409714$ & $\$ 818031$ \\
\hline $\begin{array}{c}\text { Participación } \\
\text { porcentual }\end{array}$ & $36.3 \%$ & $3.4 \%$ & $10.2 \%$ & $50.1 \%$ & $100.00 \%$ \\
\hline
\end{tabular}

Fuente: elaboración propia a partir de los datos de 2013 a 2020 de la Secretaría de Planeación y Participación Ciudadana (2020).

Mediante la revisión diacrónica de las políticas, se encontró que de 2016 a 2018 operaron el mayor número de programas, 11 de los 15 identificados, mientras que con el cambio gubernamental, a partir de 2019, se presentó una variación en las prioridades, observable en la eliminación de algunos programas, tales como Desarrollo de Productos Artesanales, Vive el Arte y los Talleres de Formación Empresarial. Pero, por otro lado, se reactivó el programa Fomento Jalisciense a la Propiedad Intelectual, con el cual se realza la necesidad de que las creaciones generen no sólo empresas y empleo, sino también especificidad, valor agregado y derechos económicos (véase figura 4).

En relación con los beneficiarios de los programas, la figura 5 muestra la comparación entre el promedio de las personas que fueron atendidas y el presupuesto medio por beneficiario, ${ }^{4}$ a partir de lo cual se demuestra que los programas que se promovieron mediante las políticas de demanda, como Vive el Arte, presentan un alto promedio de beneficiarios, aun cuando mantienen bajos promedios presupuestales, en contraste con los que tienen un presupuesto alto y poco número de beneficiarios, como el de Desarrollo de Prototipos asociado con una política de oferta, mientras que otros dos programas resaltan por tener presupuestos ajustados al número de beneficiario: Escuela de Artes, relacionado con políticas de formación de recursos humanos, e Impulso a la Innovación, Ciencia y Tecnología, también relacionado con la oferta.

4 Los datos de los beneficiarios se presentan como logaritmos naturales debido a que la información obtenida al respecto es diversa en sus clases, presenta omisiones y falta de consistencia en los años revisados. 


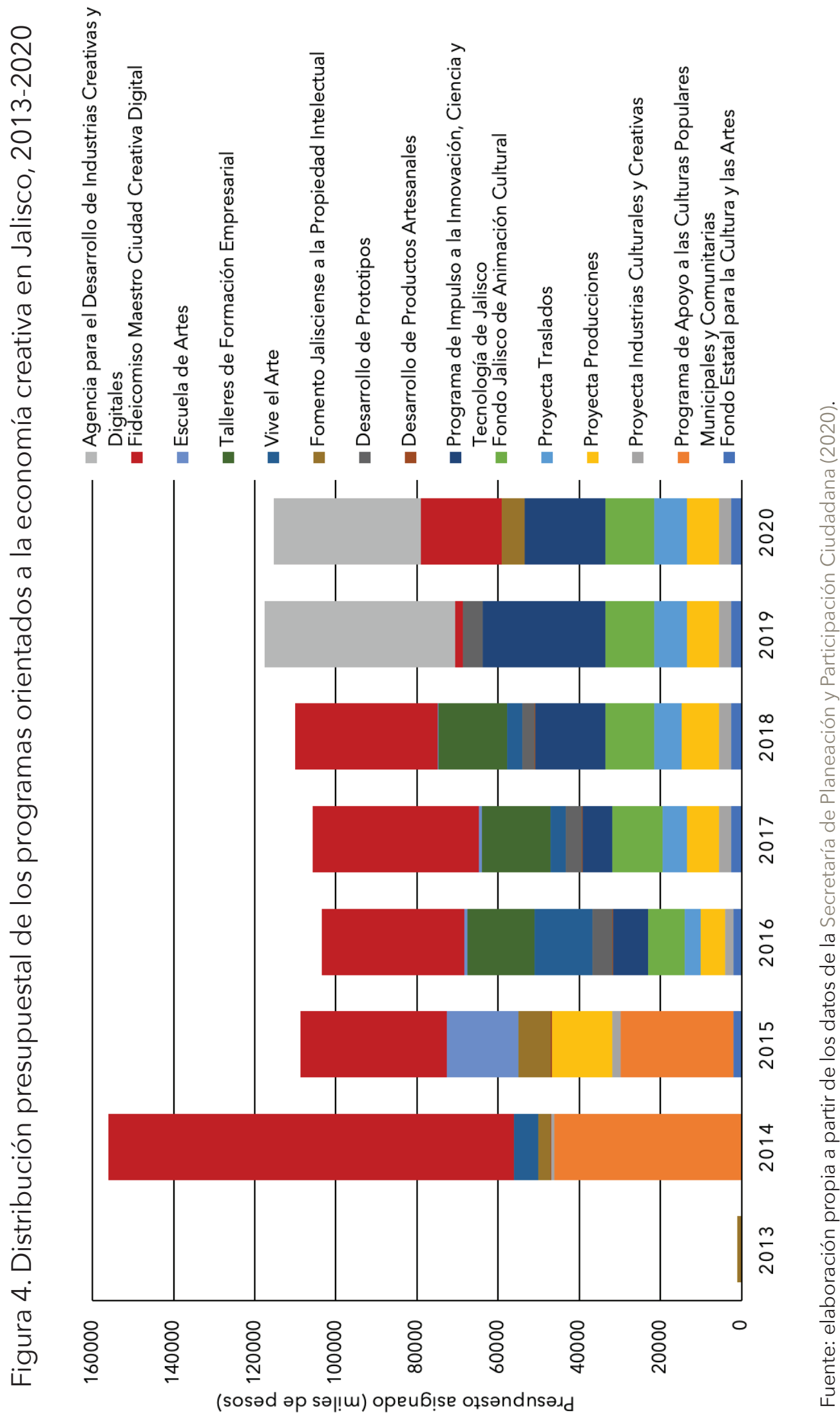


Figura 5. Comparación entre el promedio de los beneficiarios atendidos y el presupuesto promedio por beneficiario en los programas orientados a la economía creativa en Jalisco, 2013-2020

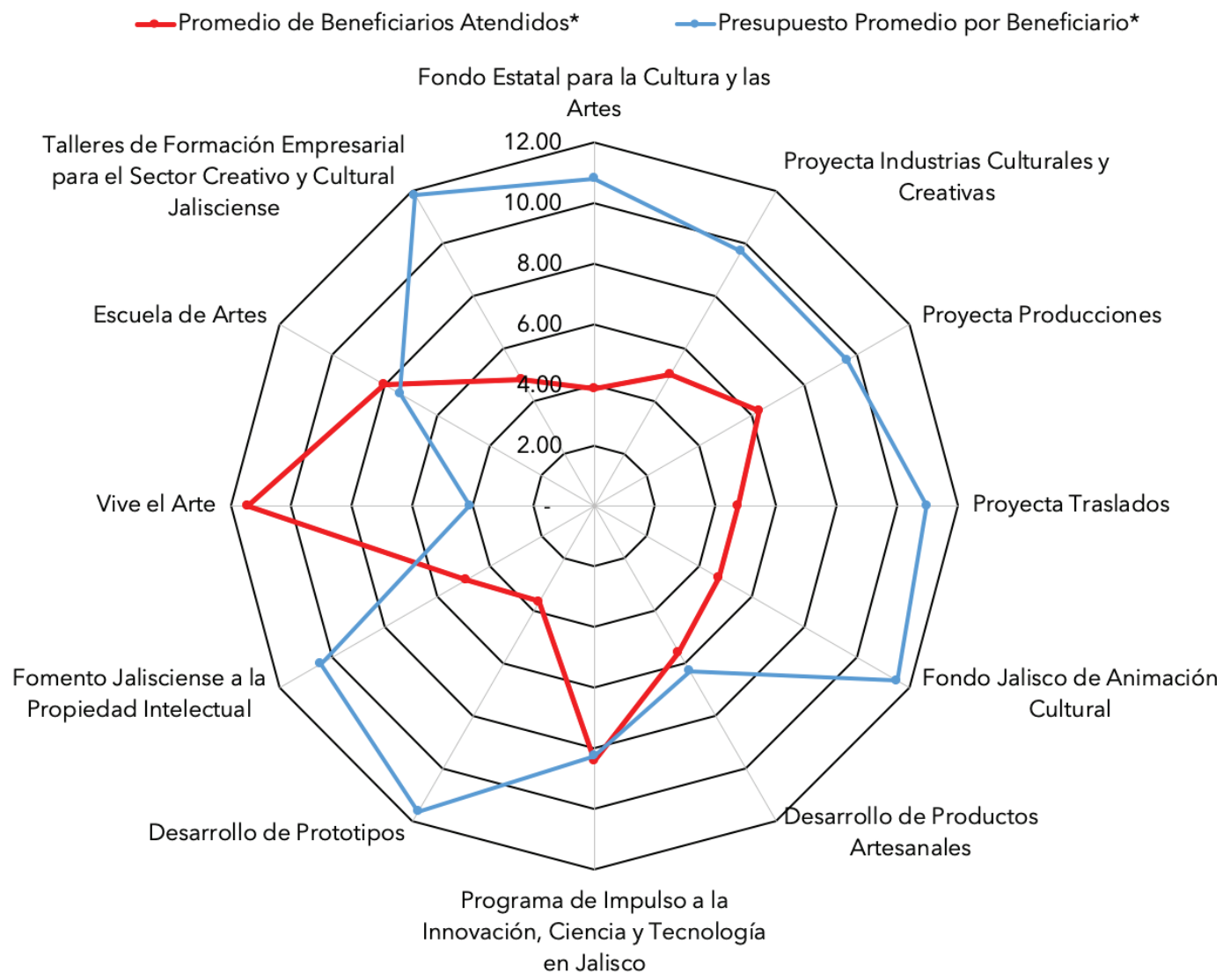

*Nota: los promedios se expresan como logaritmos naturales con el fin de realizar la comparación.

Fuente: elaboración propia a partir de los datos de la Secretaría de Planeación y Participación Ciudadana (2020).

Por otra parte, los efectos de la política pública en el estado se han materializado también en la localización empresarial de las ICC, observables en la alta concentración que presentan en el AMG, sobre todo en Guadalajara y Zapopan. Al respecto, la figura 6 muestra los coeficientes de localización por unidad económica, ${ }^{5}$ calculados para una selección proxy de cuatro subsectores y cinco

5 La fórmula utilizada en el cálculo es la siguiente:

Donde:

$$
C L i=(U i j / U j) /(U 1 / U n)
$$

$\mathrm{CL}_{1 \mathrm{i}}=$ Cociente de localización del sector de actividad 1 en la región j

$U_{1 j}=$ Unidades económicas del sector de actividad 1 en la región j

$U_{j}^{1 j}=$ Unidades económicas totales de la región j

$\bigcup_{1}^{j}=$ Unidades económicas del sector de actividad 1 en el conjunto de regiones (n)

$U^{1}=$ Unidades económicas totales en el conjunto de regiones $(n)$

$\mathrm{Si}_{\mathrm{n}}^{\mathrm{n}} \mathrm{CLi}>1$ se trata de un espacio con especialización regional en esta actividad; mientras que si $C L i<1$, no existe tal. 


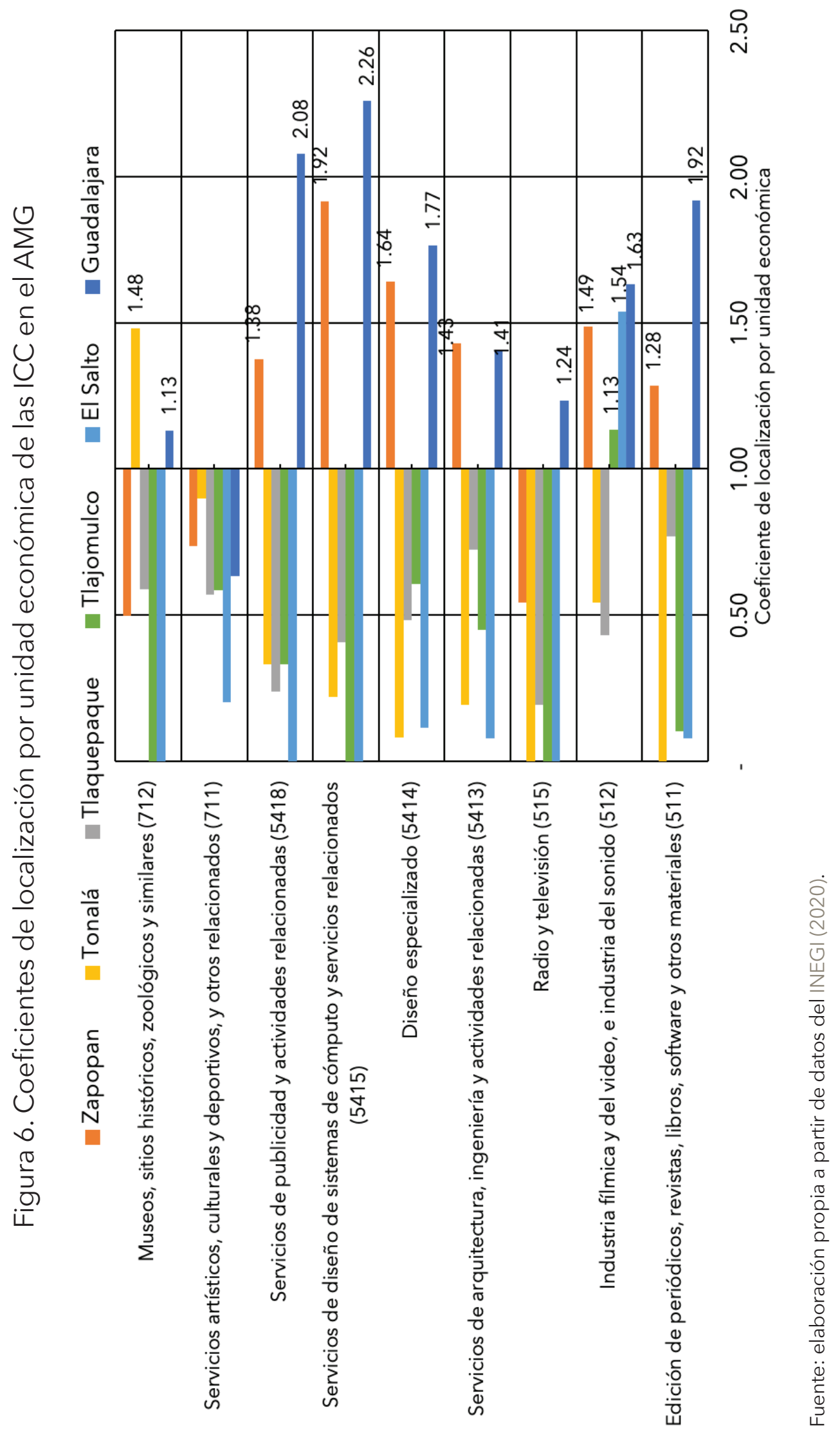


ramas de actividad, siguiendo la clasificación elaborada para Jalisco en el proyecto Mapa Trasmedia (Centro de Cultura Digital, British Council y Banco Interamericano de Desarrollo, 2019), en los que, dado un resultado mayor a la unidad, se determinó la especialización económica en servicios de diseño, servicios de cómputo (categoría censal [CC] 5415), servicios de publicidad (CC 5418), diseño especializado (CC 5414), industria fílmica, del video e industria del sonido (CC 512) y servicios de arquitectura (CC 5413).

Por ende, estos gobiernos municipales han procurado que se los catalogue como territorios culturales y creativos no sólo por la localización empresarial, sino también por los reconocimientos internacionales y nacionales asociados con la cultura y la creatividad, pues éstos deben utilizarse como marcas territoriales mediante los cuales se plantee un vocacionamiento relacionado con las ICC y su competitividad en este tipo de desarrollo. Al respecto, la tabla 3 describe las características de cuatro de ellos en tres municipios del AMG.

Tabla 3. Reconocimientos asociados con el fomento de la EC en el AMG

\begin{tabular}{|c|c|c|}
\hline $\begin{array}{c}\text { Actores } \\
\text { promotores }\end{array}$ & $\begin{array}{l}\text { Nombramiento y } \\
\text { fecha de inicio }\end{array}$ & $\begin{array}{c}\text { Características generales } \\
\text { del reconocimiento }\end{array}$ \\
\hline \begin{tabular}{|} 
Ayuntamiento \\
de Guadalajara y \\
Bureau Internacional \\
de Capitales \\
Culturales y de \\
Capital Americana \\
de la Cultura \\
\end{tabular} & $\begin{array}{c}\text { Guadalajara, } \\
\text { Capital Americana } \\
\text { de la Cultura, } \\
1 \text { de enero de } 2005 .\end{array}$ & $\begin{array}{l}\text { Con la distinción, el municipio fortaleció su } \\
\text { infraestructura cultural a partir de la obtención de } \\
\text { un mayor presupuesto federal (Marcin, 2005), aun } \\
\text { cuando el reconocimiento se orientó a que los } \\
\text { pueblos del continente americano se conozcan } \\
\text { mejor, difundan su diversidad y pongan } \\
\text { de relieve el patrimonio cultural común. }\end{array}$ \\
\hline $\begin{array}{c}\text { Ayuntamiento } \\
\text { de Guadalajara, } \\
\text { Ciudad Creativa } \\
\text { Digital, A. C., el } \\
\text { Consejo Promotor } \\
\text { de Innovación } \\
\text { y Diseño, } \\
\text { Organización de las } \\
\text { Naciones Unidas } \\
\text { para la Educación, } \\
\text { la Ciencia y la } \\
\text { Cultura, México. } \\
\end{array}$ & $\begin{array}{l}\text { Guadalajara, Ciudad } \\
\text { de las Artes Digitales } \\
\text { y miembro de la } \\
\text { Red de Ciudades } \\
\text { Creativas de la } \\
\text { UNESCO, } 8 \text { de } \\
\text { noviembre de } 2017 .\end{array}$ & $\begin{array}{c}\text { Tres objetivos se establecieron al integrarse } \\
\text { a la red: 1) cooperar con otras ciudades de } \\
\text { las artes digitales a partir del intercambio } \\
\text { y coproducciones creativas; 2) promover la } \\
\text { organización de la Reunión Anual de Ciudades } \\
\text { Creativas de Arte Digital; y 3) fortalecer la } \\
\text { industria local y sus recursos humanos } \\
\text { (Gobierno de Guadalajara, 2017). }\end{array}$ \\
\hline $\begin{array}{l}\text { Gobierno Municipal } \\
\text { de Zapopan y } \\
\text { UNESCO México. }\end{array}$ & $\begin{array}{l}\text { Declaratoria } \\
\text { Internacional } \\
\text { UNESCO-Zapopan, } \\
\text { proyecto: Capital } \\
\text { de la Cultura de } \\
\text { América Latina, } 15 \mathrm{de} \\
\text { noviembre de } 2018 .\end{array}$ & $\begin{array}{c}\text { Integra un programa de cooperación } \\
\text { internacional mediante el cual se define } \\
\text { el papel de las políticas culturales municipales } \\
\text { para la creación de comunidades sustentables, } \\
\text { en las que la cultura se sitúa en el centro } \\
\text { de su visión y acción para favorecer } \\
\text { el bienestar de las personas. }\end{array}$ \\
\hline $\begin{array}{c}\text { Gobierno de } \\
\text { Tlaquepaque, } \\
\text { Secretaría de } \\
\text { Turismo. }\end{array}$ & $\begin{array}{c}\text { Tlaquepaque Pueblo } \\
\text { Mágico, } 30 \text { de } \\
\text { octubre de } 2018 .\end{array}$ & $\begin{array}{l}\text { Con su inserción en el programa, se alienta } \\
\text { el turismo a partir del reconocimiento de sus } \\
\text { valores culturales, tales como su cultura artesanal } \\
\text { y gastronómica o los "atributos simbólicos, } \\
\text { leyendas, historia, cotidianidad y manifestaciones } \\
\text { socioculturales" (Secretaría de Turismo, s. f.) }\end{array}$ \\
\hline
\end{tabular}


En el mismo sentido, los gobiernos municipales de Guadalajara y de Zapopan en los trienios 2015-2018 y 2018-2020 han establecido objetivos en sus planes de desarrollo orientados a la cultura, similares a los estatales, como "Cultura para Todos y en Todos los Lugares" (Ayuntamiento de Guadalajara, 2016), "Garantizar el derecho a la cultura y fortalecer el desarrollo cultural comunitario" (Ayuntamiento de Guadalajara, 2019) y "Cultura como motor de desarrollo" (Gobierno de Zapopan, 2019). Con base en ello, se identificaron proyectos relacionados con PP de fomento a la oferta y demanda cultural y creativa, tales como los relacionados con los eventos culturales masivos "SUCEDE, el Festival Cultural de Guadalajara” y GDLuz Festival, realizados desde 2016 y 2017, respectivamente, cuya ejecución además aprovechó el uso de los espacios públicos de la ciudad. En relación con la formación de capital humano, se reconoce el programa Zapopan Academy, dirigido al desarrollo de talento para la industria 4.0 a través de la capacitación especializada, así como las escuelas de música y artes plásticas puestas en marcha en el Centro Cultural Constitución de Zapopan inaugurado en 2016, con objeto de alentar el desarrollo cultural y creativo de la comunidad.

\section{Conclusiones}

La construcción de una EC a partir del fomento de las ICC ha sido planteada por organismos internacionales, gobiernos nacionales y subnacionales como una vía para alentar el desarrollo, sustentado en recursos endógenos intangibles, relacionados con la cultura, el conocimiento y la generación de valor agregado, a partir de la innovación y los derechos de propiedad que se pueden producir con ellos. De ahí que, a pesar de las imprecisiones respecto de las actividades específicas que deben contemplarse, su estructura económica o el alcance real de su fomento, los gobiernos subnacionales las plantean, confiando en que con su promoción se podrá crear un desarrollo integrado, incluso solucionando los problemas de desindustrialización de sus territorios.

En este contexto, el caso de Jalisco y el AMG es evidencia de un doble origen: estructural, dado el entramado y la dinámica de los sectores de alta tecnología, software y las ramas de servicios asociados con el conocimiento presentes en la entidad desde la década de 1990 que ahora se identifican con las industrias creativas; pero también, coyuntural, por el seguimiento del gobierno del Estado de políticas originadas desde el ámbito internacional y nacional, que consideran la cultura y la creatividad como recursos que posibilitan la creación de empleos e impulsan el derecho de los creadores y sus comunidades a aprovechar sus recursos intangibles, posibilitando incluso que los gobiernos municipales busquen ser reconocidos como territorios creativos.

Por ello, dado el análisis de las PP estatales y sus impactos - respecto a los presupuestos asignados y el número de beneficiarios-, se concluye que aun cuando en Jalisco se promueven en general la construcción de una EC a través de las ICC, el proyecto principal en el que se centra la estrategia es la CCD, dados los montos de financiamiento que han recibido los dos programas instituidos para su desarrollo. En segundo término, se incorporan las políticas de oferta con 
financiamiento directo, las de demanda y de formación de recursos humanos, ejercidas en trece programas, mediante los cuales se pretende mejorar el sistema productivo cultural y creativo existente, cuya mayor incidencia se da en el AMG debido a su concentración y especialización.

Sin embargo, la amplitud de los sectores económicos contemplados en las ICC - desde los culturales hasta aquellos asociados con las tecnologías-, vuelve compleja la distinción y el planteamiento de las políticas públicas. Impone el reto de desarrollar las capacidades empresariales y creativas para los múltiples actores involucrados, con presupuestos fortalecidos, que permitan tener un mayor y mejor impacto, sea en el número de beneficiarios, el valor agregado, el desarrollo de innovaciones o la creación de derechos de PI, que permitan su desarrollo a largo plazo. Más aún, el reto se impone para los gobiernos cuando no se ha evaluado si las políticas de fomento implementadas mejoran la vida económica de las empresas y su anclaje territorial, de tal forma que generen empleos permanentes, derramas en las cadenas de valor e impactos económicos en el territorio.

Así mismo se esperaría que las políticas sistémicas estén también orientadas a generar una mayor transversalidad no sólo por su asociación con la CCD, sino también por el reforzamiento de la especialización empresarial, el aprovechamiento de las externalidades de las ICC aglomeradas en el AMG y la formación de redes, asociaciones y cadenas de valor, focalizándose en los lugares, a partir de su identificación como clústers creativos, barrios o zonas culturales según sea el caso, con lo cual los territorios municipales puedan ser nombrados como creativos no sólo por los reconocimientos otorgados por organismos e instituciones externas, sino por la localización de factores innovadores y la consolidación de comunidades creativas, que permitan identificar la vocación productiva de la metrópoli y fortalecer las políticas de desarrollo local.

De igual forma, no obstante que un gran porcentaje de las políticas identificadas en el periodo de análisis tuvieron una continuidad, aun con el cambio de partidos políticos en el poder, resulta necesario encontrar mayores evidencias que permitan validar su mantenimiento a largo plazo, no asociado sólo con la orientación de un gobierno de seis o tres años. En este sentido, si bien en los municipios de Guadalajara y Zapopan se han mantenido los objetivos y proyectos en dos periodos de gobierno, el resto de los municipios del AMG no generan políticas explícitas en sus planes de desarrollo orientadas al aprovechamiento de los recursos culturales, creativos y patrimoniales, por lo cual es recomendable impulsar su desarrollo, a fin de evitar disparidades territoriales y diferenciaciones, ahora manifiestas por la localización que las empresas de las ICC tienen.

\section{Referencias}

Aguilar Villanueva, L. F. (ed.). (1993). La implementación de las políticas. México: Miguel Ángel Porrúa.

Alonso Hierro, J., y Martín Fernández, J. (2013). Activos culturales y desarrollo sostenible: la importancia económica del patrimonio cultural. Política y So- 
ciedad, 50(3), 1133-1147. doi: https://doi.org/10.5209/rev_POSO.2013.v50. n3.41861

Arechavala Vargas, R., Rico Huerta, R., Rodríguez Barba, G., y Huerta Ruvalcaba, J. P. (2010). La empresa en el desarrollo económico: ¿basta el crecimiento? En V. M. González Romero, C. E. Anguiano Gómez y H. Gutiérrez Pulido (eds.), 2 décadas en el desarrollo de Jalisco. 1990-2010 (pp. 193-209). Guadalajara: Gobierno de Jalisco y Secretaría de Planeación.

Arellano Ríos, A. (2013). La gestión metropolitana. Casos y experiencias de diseño institucional. México: UNAM, Instituto de Investigaciones Jurídicas y El Colegio de Jalisco. Recuperado de www.juridicas.unam.mxwww.bibliojuridica.org

Arias, P. (1993). Cambio y continuidad en la vida económica tapatía. En L. F. Cabrales Barajas (eds.), Espacio urbano, cambio social y geografía aplicada (pp. 85-95). Guadalajara: Universidad de Guadalajara.

Arroyo Alejandre, J. (1993). La transición poblacional y económica de la Zona Metropolitana de Guadalajara. En L. F. Cabrales Barajas (Ed.), Espacio urbano, cambio social y geografía aplicada (pp. 97-128). Guadalajara: Universidad de Guadalajara.

Ayuntamiento de Guadalajara. (2016). Plan Municipal de Desarrollo Guadalajara 500/Visión 2042. Guadalajara: Gaceta Municipal. Recuperado de https://transparencia.guadalajara.gob.mx/sites/default/files/PMDGuadalajara2015-2018.pdf

Ayuntamiento de Guadalajara. (2019). Plan Municipal de Desarrollo y Gobernanza Guadalajara 2018-2021. Guadalajara: Gaceta Municipal. Recuperado de https://transparencia.guadalajara.gob.mx/sites/default/files/GacetaTomolVEjemplar1 Julio3-2019.pdf

Basulto Castillo, A., Hernández Pérez, A., y López Méndez, G. (2016). Políticas públicas y reconversión de la industria electrónica hacia un ecosistema de alta tecnología en Jalisco. En El desarrollo regional frente al cambio ambiental global y la transición hacia la sustentabilidad. AMECIDER, Instituto Tecnológico de Mérida, UNAM. Recuperado de http://ru.iiec.unam. mx/3283/1/090-Basulto-Hernandez-Lopez.pdf

Benavente, J. M., y Grazzi, M. (2017). Políticas públicas para la creatividad y la innovación: impulsando la economía naranja en América Latina y el Caribe. Banco Interamericano de Desarrollo. Recuperado de http://publications. iadb.org/publications/spanish / document/Políticas-públicas-para-la-creatividad-y-la-innovación-Impulsando-la-economía-naranja-en-América-Latina-y-el-Caribe.pdf

Benhamou, F. (2009). Economía y cultura. En C. Asuaga (ed.), Un encuentro no casual: cultura, ciencias económicas y derecho (primera edición, pp. 11-19). Montevideo: Fundación de Cultura Universitaria. https://books.google.com. $\mathrm{cu} /$ books?id=8s6EjMuU4rOC\&printsec=frontcover\&hl=es\&source=gbs_ge_ summary_r\&pli $1 \# \mathrm{H}=$ onepage\&q\& $\mathrm{f}=$ false

Boix, R., y Lazzeretti, L. (2012). Las industrias creativas en España: una panorámica. Investigaciones Regionales, 22, 181-205. Recuperado de http://www. redalyc.org $/$ articulo.oa?id=28923184009 
Buitrago Restrepo, F., y Duque Márquez, I. (2013). La economía naranja. Una oportunidad infinita. Bogotá: Banco Interamericano de Desarrollo.

Capital Americana de la Cultura. (s. f). Recuperado de http: / /www.cac-acc.org/ present.php?lang=sp

Caravaca Barroso, I., González Romero, G. , Fernández Salinas, V., y García García, A. (2013). Economía creativa en la aglomeración metropolitana de Sevilla: agentes, redes locales de colaboración y principales actuaciones. Boletín de la Asociación de Geógrafos Españoles 63, 81-103. doi: https://doi. org/10.21138/bage.1607

Centro de Cultura Digital, British Council y Banco Interamericano de Desarrollo. (2019). Mapa transmedia. Recuperado de https://centroculturadigital.mx/ mapa-transmedia/

Conferencia de las Naciones Unidas sobre Comercio y Desarrollo (UNCTAD). (2008). Resumen. Informe sobre la economía creativa 2008. Recuperado de http://www.unctad.org/

Conferencia de las Naciones Unidas sobre Comercio y Desarrollo (UNCTAD). (2010). Economía creativa. Informe 2010. Nueva York.

Congreso del Estado de Jalisco. (2019). Decreto número 27232/LXII/19. Guadalajara: Periódico Oficial del Estado de Jalisco. Recuperado de https://periodicooficial.jalisco.gob. mx/sites/periodicooficial.jalisco.gob. mx/ files/02-0219-viii.pdf

Consejo Estatal de Ciencia y Tecnología de Jalisco. (2003). Programa Estatal de Ciencia y Tecnología del Estado de Jalisco, PECYTJAL 2001-2007. Guadalajara: Gobierno de Jalisco, Secretaría de Promoción Económica.

Florida, R. (2012). The rise of the creative class. Revisited. Nueva York: Basic Books.

Gobierno del Estado de Jalisco. (2013). Presentan la nueva dirección de Industrias Creativas de la SC. Recuperado de https://www.jalisco.gob.mx/es/ prensa/noticias/6189

Gobierno del Estado de Jalisco. (2019). Plan Institucional Ciudad Creativa Digital. Guadalajara: Periódico Oficial del Estado de Jalisco. Recuperado de https://periodicooficial.jalisco.gob.mx/sites/periodicooficial.jalisco.gob.mx/ files/10-19-19-x.pdf

Gobierno de Guadalajara. (2017). Guadalajara, Ciudad de las Artes Digitales y miembro de la Red de Ciudades Creativas de la UNESCO. Recuperado de https://guadalajara.gob.mx/noticias/guadalajara-ciudad-artes-digitales-miembro-red-ciudades-creativas-unesco

Gobierno de Zapopan. (2019). Plan Municipal de Desarrollo y Gobernanza 20182021. Gaceta Municipal Ayuntamiento de Zapopan.

Graglia, J. E. (2014). Políticas públicas para el desarrollo local y regional. Buenos Aires: Konrad-Adenauer-Stiftung y Asociación Civil Estudios Populares.

Greffe, X. (2017). La ciudad creativa. En Autor, Ciudades creativas. Conceptos, políticas y actores (pp. 42-77). Barcelona: Kreanta Editorial, Fundación Kreanta. Recuperado de http://kreantaeditorial.org/wp-content/ uploads/2020/03/Kreanta-Editorial_CIUDADES-CREATIVAS_ebook.pdf 
Hernández Barba, A. (2009). Políticas culturales, congruencia entre la institución y la organización de la acción pública. Revista Folios, 2(13), 42-54. Recuperado de http: / / www. revistafolios.mx/hemeroteca

Hesmondhalgh, D., y Pratt, A. C. (2005). Cultural industries and cultural policy. International Journal of Cultural Policy, 11(1), 1-13. doi: https://doi. org/10.1080/10286630500067598

Howkins, J. (2013). The creative economy. How people make money from ideas. Londres: Penguin Books.

Instituto Nacional de Estadística y Geografía (INEGI). (2013). Cultura. Base 2013. Metodología. Recuperado de https://www.inegi.org.mx/contenidos/programas/cultura/2013/doc/met_cscm.pdf

Instituto Nacional de Estadística y Geografía (INEGI). (2014). Sistema Automatizado de Información Censal (SAIC). Recuperado de http://www.beta.inegi. org. mx/app/saic/default.aspx

Instituto Nacional de Estadística y Geografía (INEGI). (2018a). Banco de Información Económica (BIE). Recuperado de http: / / www.inegi.org.mx/sistemas / bie/

Instituto Nacional de Estadística y Geografía (INEGI). (2018b). Cultura. Recuperado de https://www.inegi.org.mx/temas/cultura/default.html\#Tabulados

Instituto Nacional de Estadística y Geografía (INEGI). (2020). Directorio Estadístico Nacional de Unidades Económicas. Recuperado de https://www.inegi. org.mx/app/mapa/denue/default.aspx

Knoepfel, P., Larrue, C., Varone, F., y Dieck, M. H. (2007). Hacia un modelo de análisis de políticas públicas operativo. Un enfoque basado en los actores, sus recursos y las instituciones. Ciencia Política, 2(3). Recuperado de https:// revistas.unal.edu.co/index.php/cienciapol/article/view/17521

Kong, L. (2014). From cultural industries to creative industries and back? Towards clarifying theory and rethinking policy. Inter-Asia Cultural Studies, 15(4), 593-607. doi: https://doi.org/10.1080/14649373.2014.977555

Lash, S., y Urry, J. (1998). Economías de signos y espacio. Buenos Aires: Amorrortu Editores.

Lazzeretti, L., Boix, R., y Capone, F. (2012). Why do creative industries cluster? En L. Lazzeretti (ed.), Creative Industries and Innovation in Europe (p. 328). Londres: Routledge. doi: https://doi.org/10.4324/9780203112571

Lazzeretti, L., Capone, F., e Innocenti, N. (2017). European planning studies exploring the intellectual structure of creative economy research and local economic development: a co-citation analysis exploring the intellectual structure of creative economy research and local economic development: a co-citation analysis. European Planning Studies, 25(10), 1693-1713. doi: https: / / doi.org/10.1080/09654313.2017.1337728

Lazzeretti, L., y Cinti, T. (2012). From cultural cluster to creative cluster. The case of art restoration in Florence. En L. Lazzeretti (ed.), Creative Industries and Innovation in Europe: Concepts, Measures and Comparative Case Studies (pp. 175-193). Taylor y Francis Group. Recuperado de http://ebookcentral. proquest.com/lib/wdgbiblio/detail.action?doclD=1016184. 
Lozano Uvario, K. M., Méndez Guardado, P., y Castañeda Castro, R. (2018). Políticas públicas y economía naranja en la región Valles de Jalisco, México. Córima, Revista de Investigación en Gestión Cultural, 3(4), 1-28. doi: https: // doi.org/10.32870/cor.a3n4.7068

Lozano Uvario, K. M., Méndez Guardado, P., y González Torreros, L. (2018). La economía naranja en el espacio rural: análisis desde el desarrollo local en la Región de las Vías Verdes de los Valles, Jalisco. Revista Iberoamericana de Vitivinicultura, Agroindustria y Ruralidad, 5(14). Recuperado de https: / / www. redalyc.org/jatsRepo/4695/469554838002/html/index.html

Marcin, M. (17 de enero 2005). Guadalajara, Capital Americana de la Cultura, impulsará cultura local. Cultura. Recuperado de http://www.cronica.com. mx/notas/2005/162438.html

Markusen, A., y Gadwa, A. (2010). Creative Placemaking. Washington: National Edowment for The Arts. Recuperado de http://arts.gov/pub/pubDesign.php.

Markusen, A., Wassall, G. H., y Denatale, D. (2008). Defining the Creative Economy: Industry and Occupational Approaches. Economic Development Quarterly, 22(1), 24-45. doi: https://doi.org/10.1177/0891242407311862

Méndez, R., Michelini, J., Prada, J., y Tébar, J. (2012). Economía creativa y desarrollo urbano en España: una aproximación a sus lógicas espaciales. Eure, 38(133), 5-32. Recuperado de https://scielo.conicyt.cl/pdf/eure/v38n113/ art01.pdf

Moeglin, P., y Tremblay, G. (2013). Industrias culturales y políticas en torno a la creación y a su regimen de propiedad intelectual. En D. Crovi Druetta (ed.), Industrias culturales en México. Reflexiones para actualizar el debate (pp. 61-87). México: Universidad Nacional Autónoma de México y Productora de Contenidos Culturales Sagahón Repoll.

Negrete, J. F. (2013). El impacto de las nuevas tecnologías en las industrias creativas. El caso de la industria de la música. En D. Crovi Druetta (ed.), Industrias culturales en México. Reflexiones para actualizar el debate (pp. 245-264). Ciudad de México: Universidad Nacional Autónoma de México y Productora de Contenidos Culturales Sagahón Repoll.

Newbigin, J. (2017). New and Changing Dynamics. How the Global Creative Economy is Evolving. Recuperado de https: / /creativeconomy.britishcouncil.org/ media/resources/BC_CE_New_and_Changing_Dynamics_2017.pdf

Ordóñez, S. (2017). Sistemas de innovación y conocimiento: el caso de Jalisco, México. Problemas del Desarrollo. Revista Latinoamericana de Economía, 48(191). doi: https: //doi.org/10.22201/iiec.20078951e.2017.191.59311

Organización de las Naciones Unidas para la Educación, la Ciencia y la Cultura (UNESCO). (2010). Políticas para la creatividad. Guía para el desarrollo de las industrias culturales y creativas. Paris, Francia. Recuperado de https:// es.unesco.org/creativity/sites/creativity/files/220384s.pdf

Organización de las Naciones Unidas para la Educación, la Ciencia y la Cultura (UNESCO) en México. (2018). Zapopan. Políticas culturales para el desarrollo de la comunidad en áreas metropolitanas. Ciudad de México: Unesco y Gobierno de Zapopan. 
Palacios Lara, J. J. (2008). Alianzas público-privadas y escalamiento industrial. El caso del complejo de alta tecnología de Jalisco, México. Serie Estudios y Perspectivas. México: CEPAL y Naciones Unidas.

Palma, L., y Aguado, L. (2010). Economía de la cultura. Una nueva área de especialización de la economía. Revista de Economía Institucional, 12(22 SE-Artículos). Recuperado de https://revistas.uexternado.edu.co/index.php/ ecoins/article/view/386

Peters, M. A., y Araya, D. (2010). Education in the Creative Economy: Knowledge and Learning in the Age of Innovation. Nueva York: Peter Lang. Recuperado de https://books.google.com.mx/books?hl=esylr=yid=6L-UNaQk1iwCyoi=fndypg=PA3ydq=what\%27s+creative+economyyots=uKQlkJkeR-ysig=a7 $r$ kx07m5XoUK5ppq4y8sJiJ2j4yredir_esc=y\#v=onepageyq=what's creative economyyf=false

Piedras, E. (2006). Industrias y patrimonio cultural en el desarrollo económico de México. Cuicuilco, 13(38), 29-46. Recuperado de http://www. redalyc. org/pdf/351/35103803.pdf

Programa de las Naciones Unidas para el Desarrollo (PNUD) y Organización de las Naciones Unidas para la Educación, la Ciencia y la Cultura (UNESCO). (2014). Informe sobre la economía creativa. Edición especial 2013. Ampliar los causes de desarrollo local. Nueva York. Recuperado de http: //www.unesco.org/ culture/pdf/creative-economy-report-2013-es.pdf

Sánchez Gardey, G. (2014). 9.2 Impacto económico de la cultura. Metodologías. En Universidad de Cadiz (Ed.), Manual atalaya. Apoyo a la gestión cultural (pp. 1-12). Recuperado de http:/ / atalayagestioncultural.es/pdf/09.2.pdf

Scott, A. J. (2017). Ciudades creativas: temas conceptuales y problemas de políticas. En Autor, Ciudades creativas. Conceptos, políticas y actores (pp. 1141). Barcelona: Kreanta Editorial y Fundación Kreanta.

Secretaría de Cultura Jalisco (SCJ). (2018). Programa Estatal de Cultura Jalisco 2013-2018. Plan Institucional de la Secretaría de Cultura Jalisco. Gobierno del Estado de Jalisco.

Secretaría de Planeación y Participación Ciudadana. (2020). Sistema de monitoreo de acciones y programas públicos. Recuperado de https://programas. app.jalisco.gob.mx/programas/sistemaDeProgramasPublicos

Secretaría de Turismo. (s. f.). Pueblos Mágicos de México. Recuperado de https://www.gob.mx/sectur/articulos/pueblos-magicos-206528

Szpilbarg, D., y Saferstein, E. A. (2014). De la industria cultural a las industrias creativas: un análisis de la transformación del término y sus usos contemporáneos. Estudios de Filosofía Práctica e Historia de las ideas, 16(2), 99-112. Recuperado de https: / / dialnet.unirioja.es/servlet/articulo?codigo=5718866

Tepper, S. J. (2002). Creative assets and the changing economy. The Journal of Arts Management, 32(2), 159-168. doi: https://doi. org/10.1080/10632920209596971

Throsby, D. (2000). Economics and Culture. Cambridge: Cambridge University Press. doi: https://doi.org/10.1017/cbo9781107590106

Toussaint Alcaraz, F. (2013). Evolución de las industrias de la cultura (1980-2010). En D. Crovi Druetta (ed.), Industrias culturales en México. Reflexiones para 
actualizar el debate (pp. 41-60). México: Universidad Nacional Autónoma de México y Productora de Contenidos Culturales Sagahón Repoll.

Universidad de Guadalajara. (16 de octubre de 2015). Una industria creativa y cultural en construcción. Gaceta UDG. Recuperado de http://www.gaceta. udg. mx/una-industria-creativa-y-cultural-en-construccion/

Valdivia López, M., y Cuadrado-Roura, J. R. (2017). Introducción. En M. Valdivia López y J. R. Cuadrado-Roura (eds.), La economía de las actividades creativas. Una perspectiva desde México y España (pp. 11-23). Cuernavaca: UNAM, Centro Regional de Investigaciones Multidisciplinarias.

Vázquez Barquero, A. (2000). Desarrollo local y territorio. En B. Pérez Ramírez y E. Carrillo Benito (eds.), Desarrollo local: manual de uso (pp. 93-107). Madrid: ESIC Editorial-FAMP.

Vila Seoane, M. (2017). Cultura Viva, a challenge to the creative economy policy discourse in Brazil. Bulletin of Latin American Research, 36(4), 424-439. doi: https://doi.org/10.1111/blar.12637

Woo Gómez, G. (2003). Desarrollo y políticas regionales: un enfoque alternativo. México: Instituto Tecnológico y de Estudios Superiores de Occidente.

Zarlenga, M. I., Rius-Ulldemolins, J., y Rodríguez Morató, A. (2016). Cultural clusters and social interaction dynamics: the case of Barcelona. European Urban and Regional Studies, 23(3), 422-440. Recuperado de https: / / journals-sagepub-com.wdg.biblio.udg.mx:8443/doi/pdf/10.1177/0969776413514592 